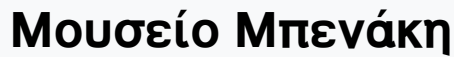

Tóp. 10 (2010)

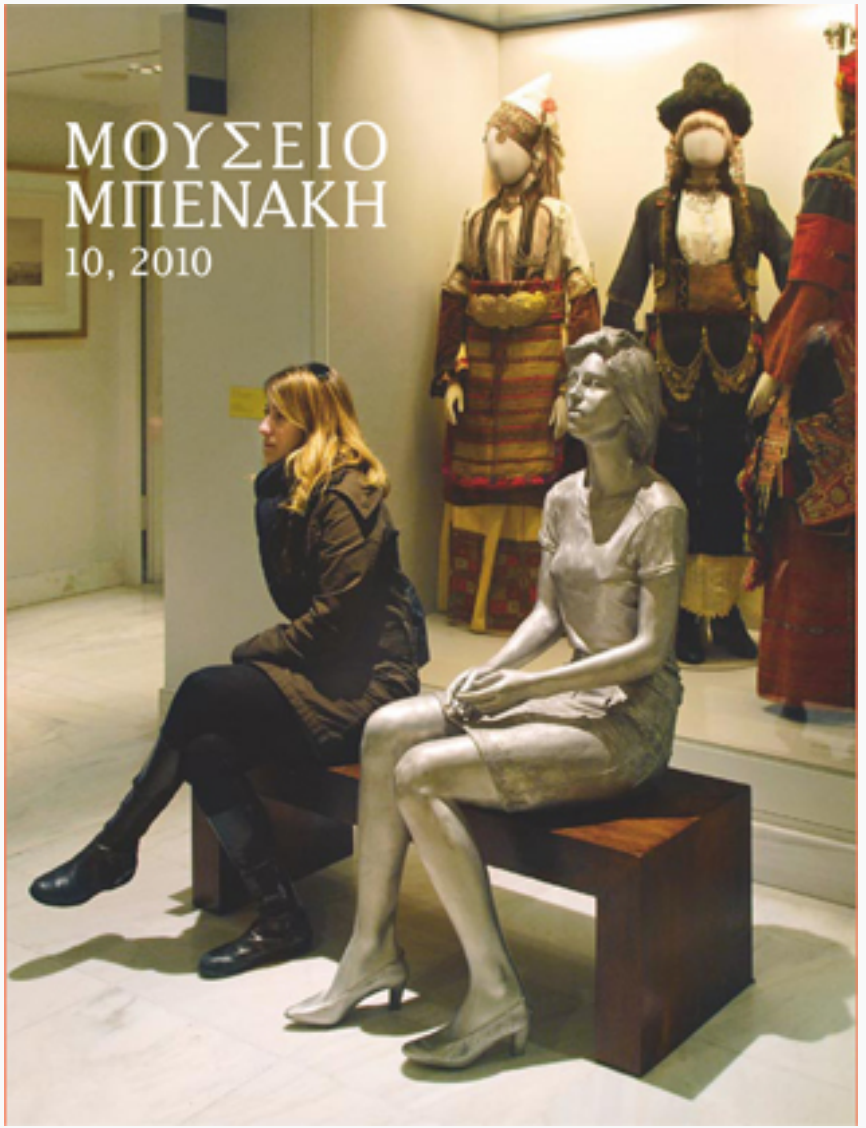

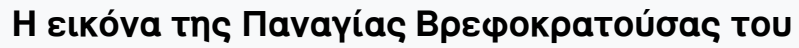

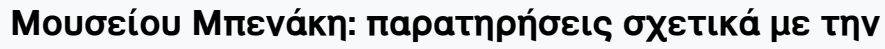

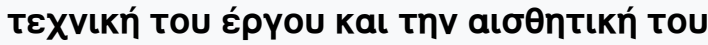
aпokatáotaơn

\section{Kalypso Milanou}

doi: $\underline{10.12681 / \text { benaki.26 }}$

\section{Bıßлıүрачıкń avaфopá:}

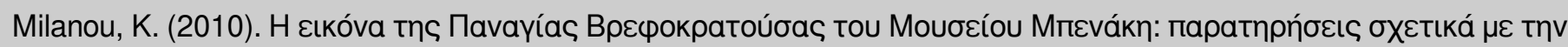

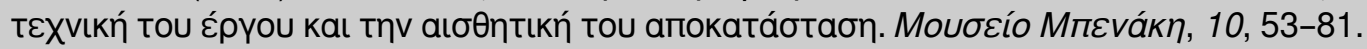

https://doi.org/10.12681/benaki.26 


\section{A Thirteenth-Century Icon of the Virgin and Child in the Benaki Museum: Observations on its Technique and Restoration}

THIS TEXT RECORDS observations and conclusions arising during the icon's conservation ${ }^{1}$ and which have contributed to a fuller understanding and more precise dating of the work (fig. 1). ${ }^{2}$ They are based on the study of the technique and the pigments employed by the painter using special photographic methods, examination in the visible, infrared and ultraviolet ranges of the spectrum, and X-radiation of the work. Microscopic examination of the paint surface and analysis of the pigments and ground from cross-sections also contributed useful data. The information obtained by these methods leads us to suggest that the icon should be dated to the thirteenth century.

\section{Description of the icon}

The figures in the Benaki Museum icon of the Virgin and Child, inv. no. 3764, stand out against a later gold ground, which was covered with a metal revetment made up of eight parts $^{3}$ (fig. 2). The Virgin is turning her head towards the Christ Child, tenderly holding his right hand. The Child lifts his hand up to be kissed by his mother, ${ }^{4}$ while turning his head to the left.

State of preservation of the work and later interventions

The support is made up of a single plank of wood, measuring $30.5 \times 22.5 \mathrm{~cm}$ and $1.8 \mathrm{~cm}$ thick. In order to better preserve the work the back was covered with a fine coat of gesso ground, of which only a small part remains intact at the bottom of the panel (fig. 3). The upper part shows significant damage from wood-boring insects which have created superficial tunnels in the wood. The front of the panel has an integral, carved frame of varying width (2.5$3.0 \mathrm{~cm})$. On the right it is even narrower $(2 \mathrm{~cm})$ and is emphasized with a band of red.

X-radiation enabled us to establish precisely the extent of any damage both to the paint layer and the support. Later overpainting can be pinpointed on the right side of the background and in the upper part of the surrounding frame. The tiny tunnels made by wood-boring insects are clearly recorded especially in the upper part of the panel. On the support small nails are preserved all around the frame, while round the haloes and the figures holes are visible from the nails which fixed the silver revetment. Given the small scale of the panel no canvas was used under the ground (fig. 4).

Extensive examination through an optical microscope in combination with the methods noted below proved that the icon had been restored at various times. 5 The earliest intervention is located on the background, which was regilded and inscribed with the initials $M P-\Theta Y$ (Mother of God) and $I C-X C$ (Jesus Christ) in cinnabar. The red band on the frame and the red line around the two haloes were added above the oxidized varnish which covered the paint layer of the original background (see fig. 1). We can posit that the gold background may have been renewed because of the discoloration of the original varnish.

In a later intervention on the background, a thin layer of gesso and gold leaf was added over a second layer of oxidized varnish. This was found mostly at the upper right side of the panel, and in the upper part of the frame. The letters 


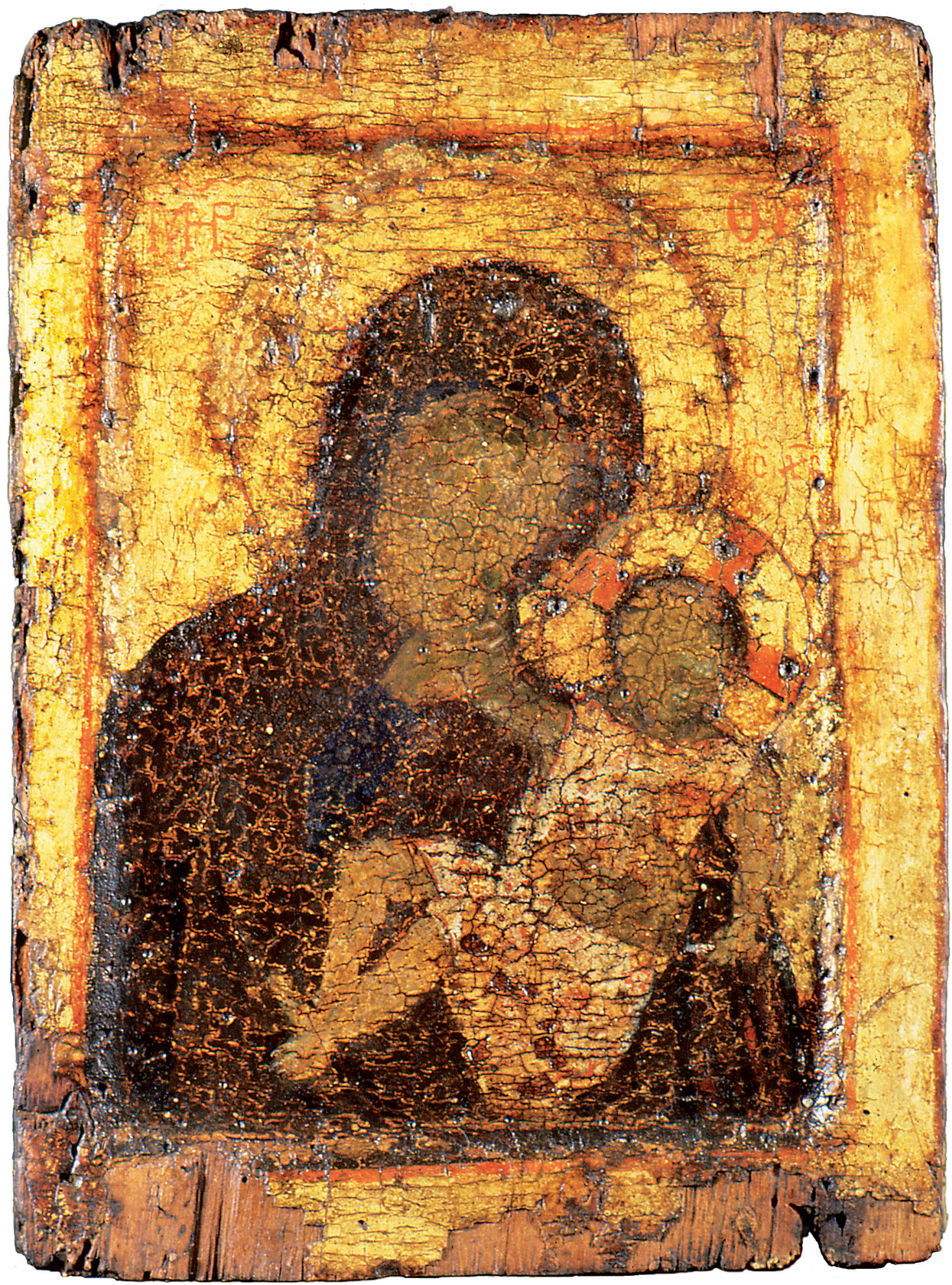

Fig. 1. Virgin and Child, after conservation and restoration. Athens, Benaki Museum, inv. no. 3764. 


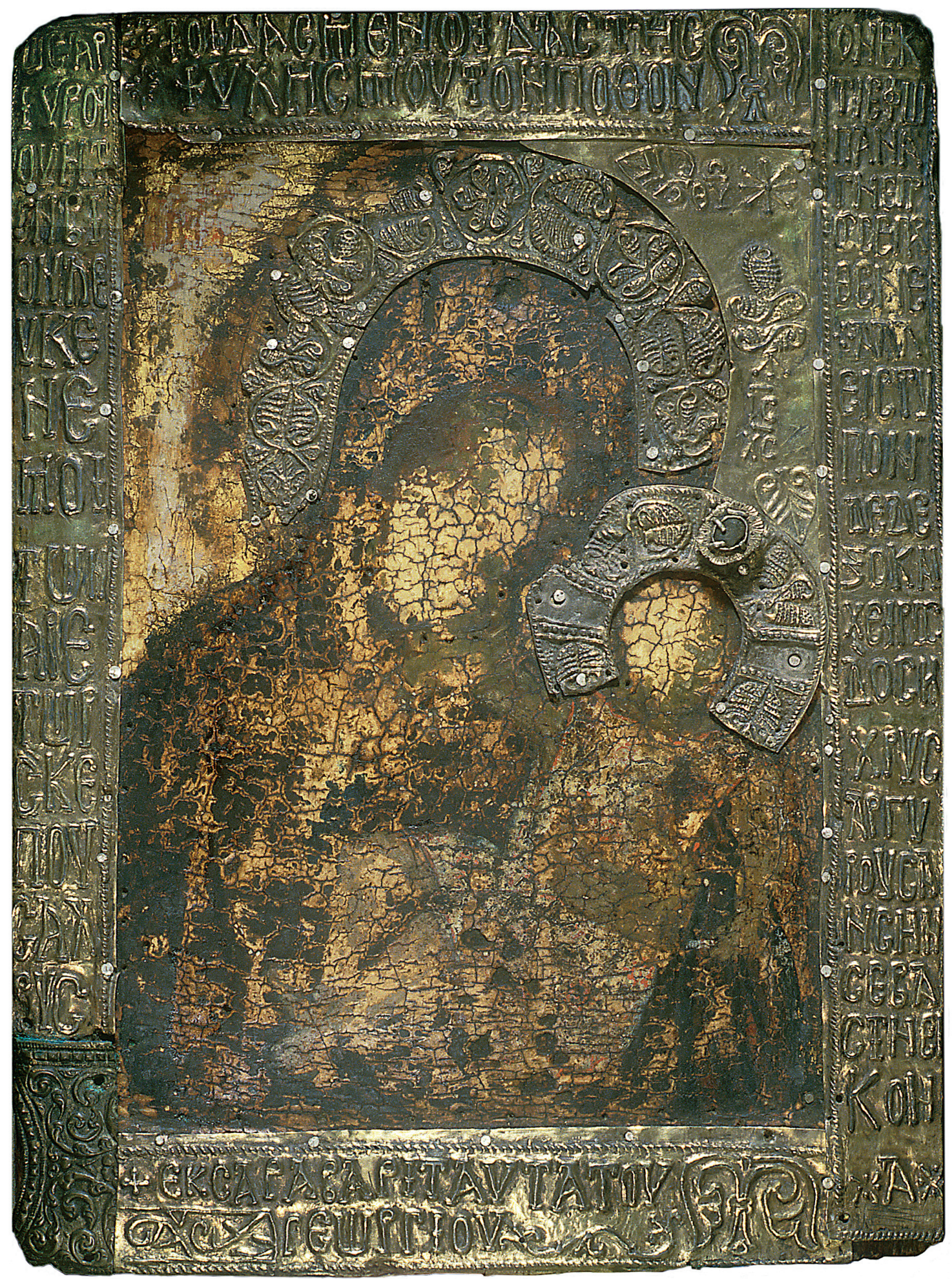

Fig. 2. Virgin and Child, with metal revetment before conservation and restoration. 


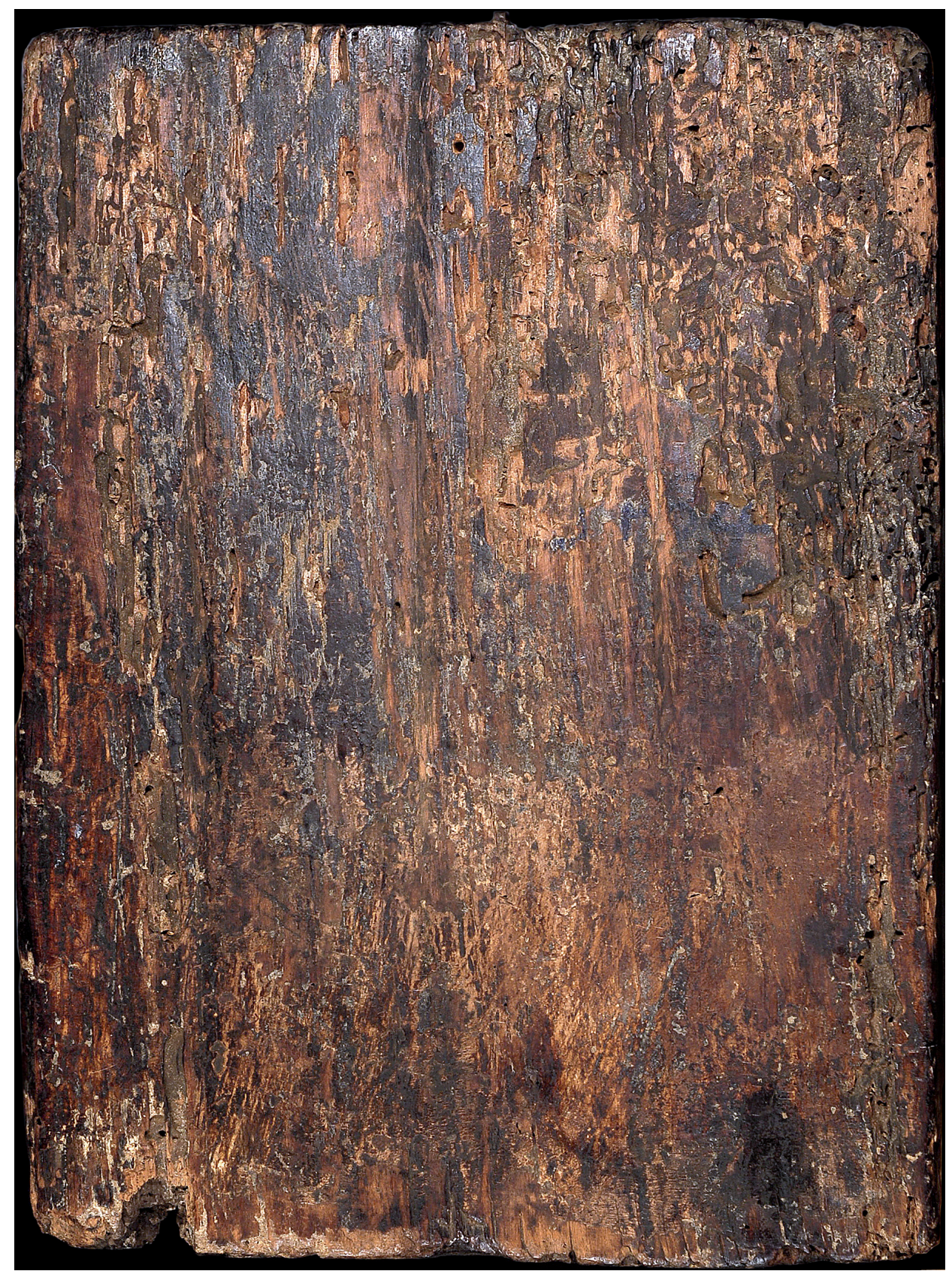

Fig. 3. Virgin and Child (reverse), partially covered with a layer of gesso and showing damage from wood-boring insects.

$M P-\Theta Y$ and $I C-X C$ were also added at this point (see fig. 4). During conservation this last layer was removed, while the older gold leaf and the letters from the earlier addition were retained intact (see fig. 1). The inpainting found on Christ's off-white tunic may date to this second intervention. A red line on the edges of the tunic and red decorative motifs, painted directly above the damaged parts of the ground, which cover old craquelure, belong to this later phase. The addition of black and white brushstrokes on the edges of the Virgin's maphorion also seem to belong to this phase (fig. 5). Now that the silver revetment has been dated to the thirteenth century, we can posit that these interventions 


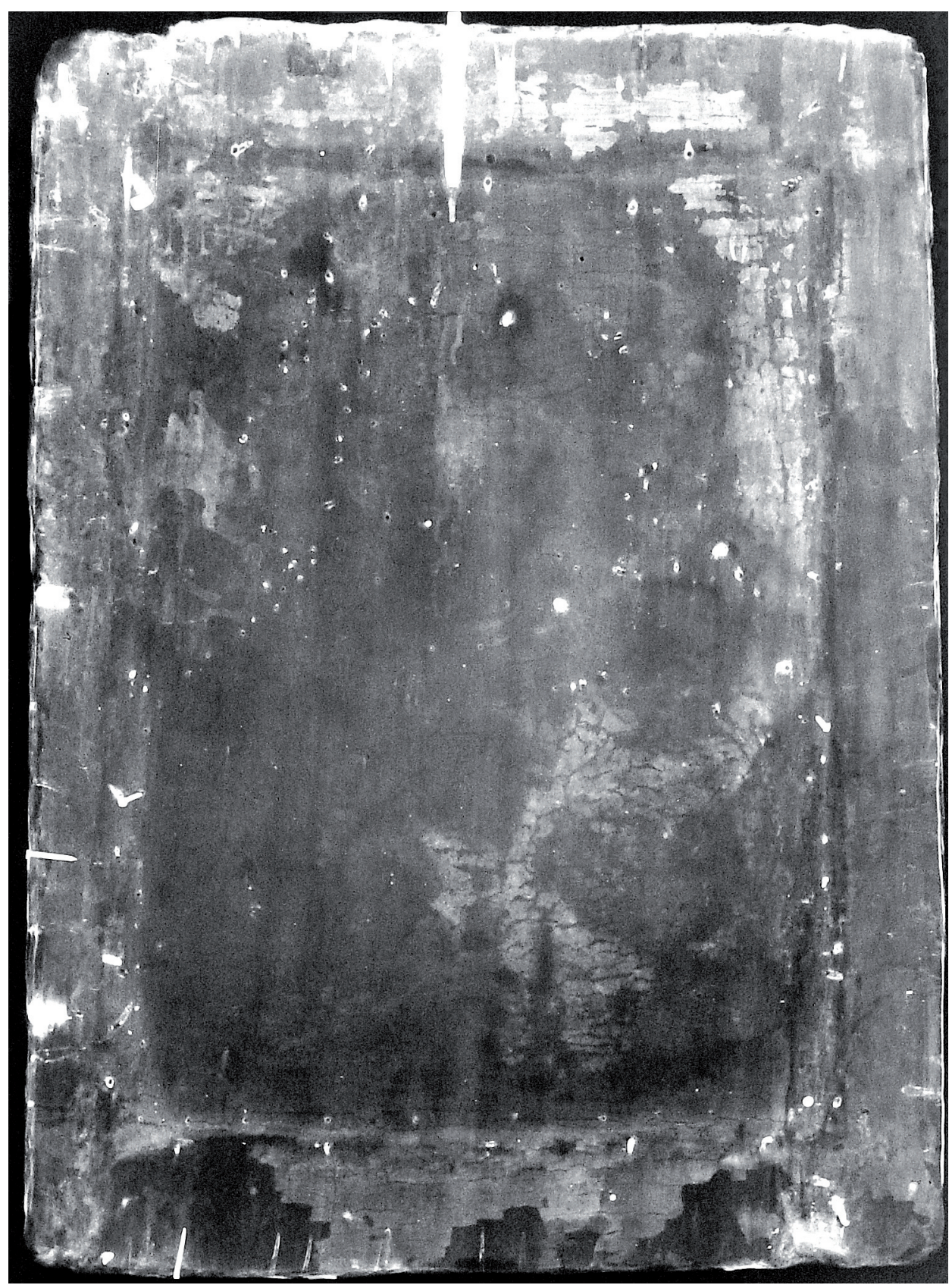

Fig. 4. Virgin and Child, X-radiography in which can be seen the overpainting, damage caused by wood-boring insects and the nails fixing the silver revetment.

were made at an even earlier stage, as there are signs and documentary evidence of the conservation of important icons from as early as the mid-twelfth century. ${ }^{6}$

In turn a third intervention, which resulted in discoloration of the area, was recorded using ultraviolet light in the upper right part of the Virgin's face (fig. 6). Moreover parts of the red band were retouched on the damaged ground of the raised frame and in damaged areas on some of the earlier lettering $(M P-\Theta Y$ and $I C-X C)$ which remained on the work after its restoration.

As regards the preservation of the original painting large areas of paint loss are discernible in all paint layers, above 


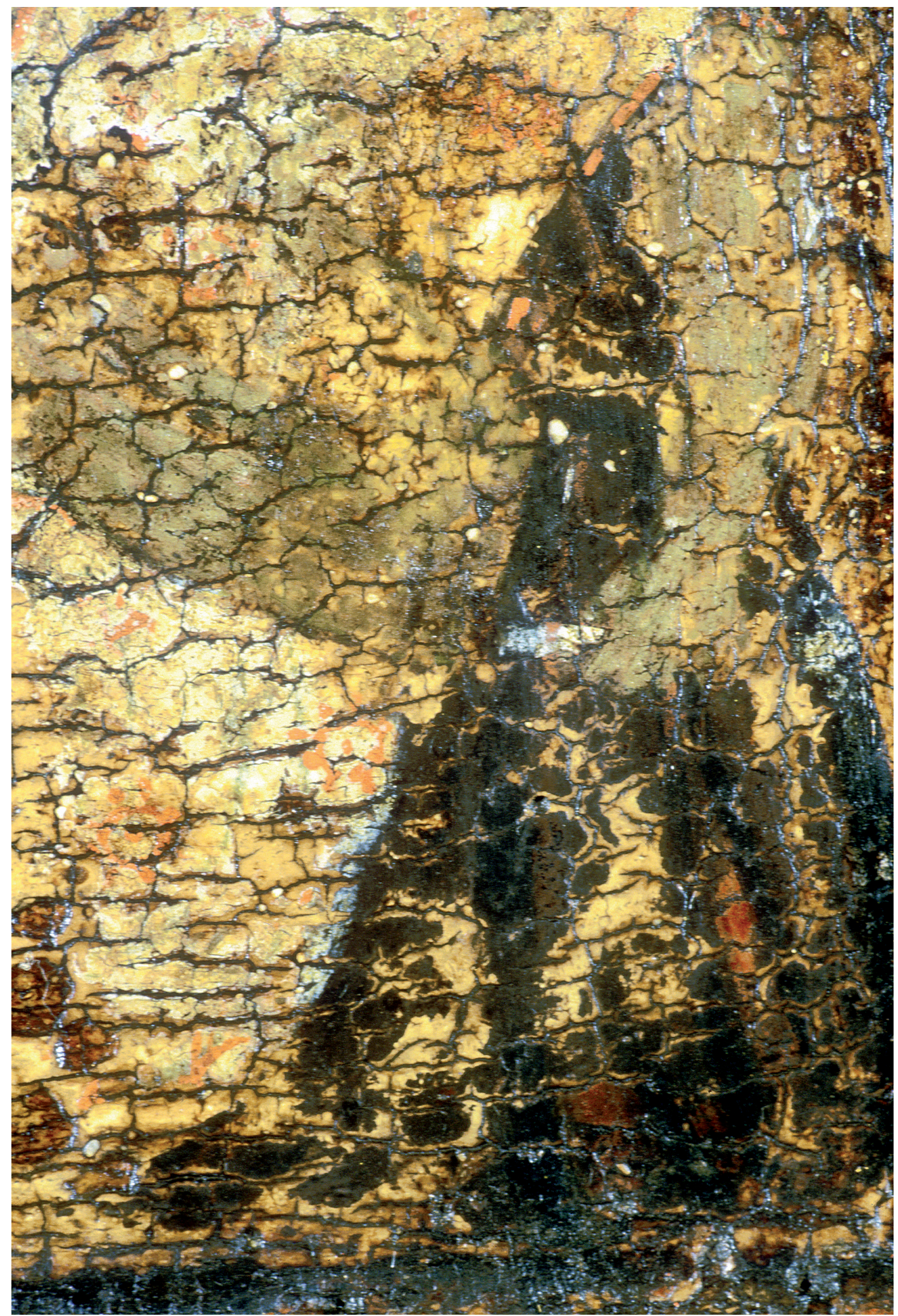

Fig. 5. Detail showing overpaintings: traces of a red line at the edge of Christ's tunic, red decorative motifs painted directly onto the damaged areas, black and white brushstrokes on the border of the Virgin's maphorion. 


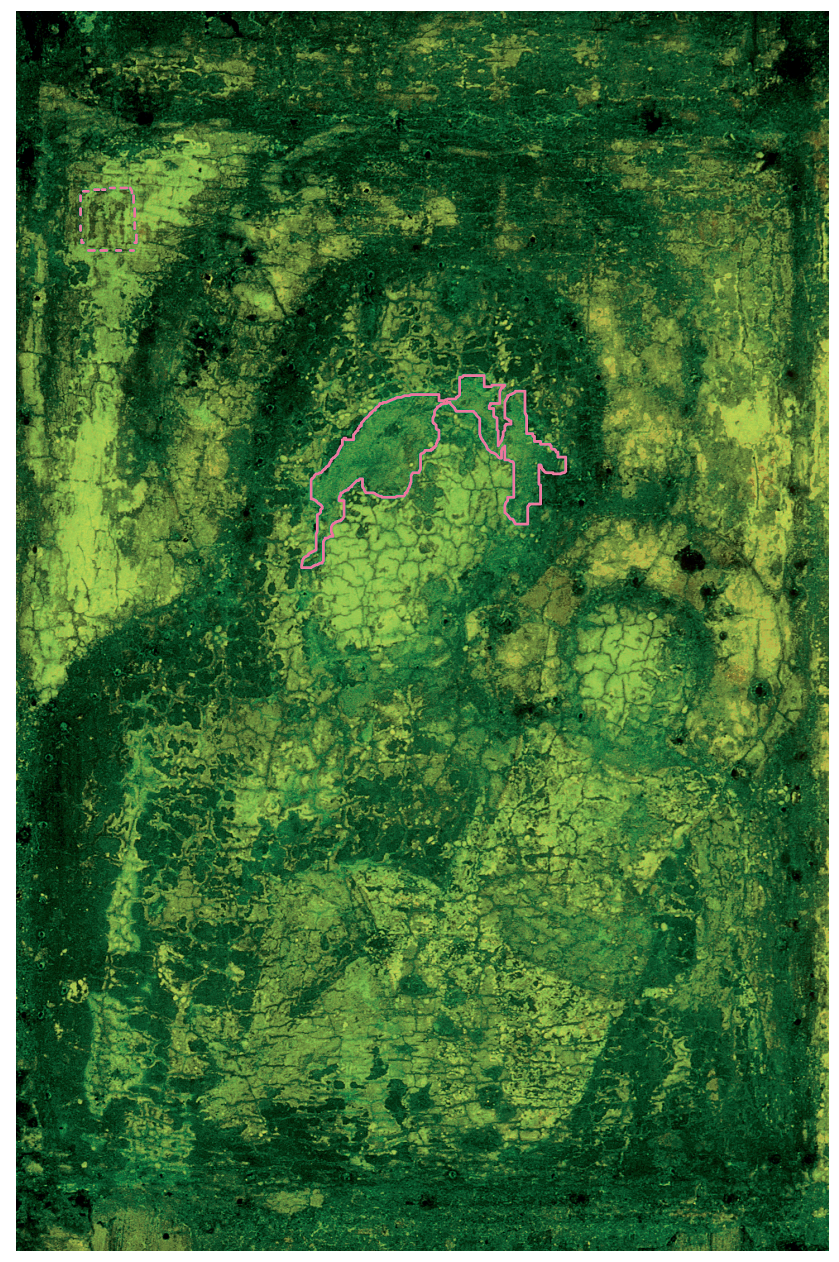

Fig. 6. Ultraviolet fluorescence in which the later inpainting can be clearly made out.

all on the face of the Virgin, the head and parts of the face of the Christ Child and their naked flesh. Parts of the Virgin's maphorion, the sleeve of her robe and from the Christ Child's tunic are also missing (fig. 7).

\section{Painting Method}

\section{Drawing}

Using infrared photography it was ascertained that the artist used a painted design on the ground. It is clearly visible around the head of the Christ Child, starting at his left shoulder, on the outlines of his tunic, and on the Virgin's left hand. A broad brushstroke on the lower part of the sleeve of the Virgin's robe can be clearly seen due not only to the level

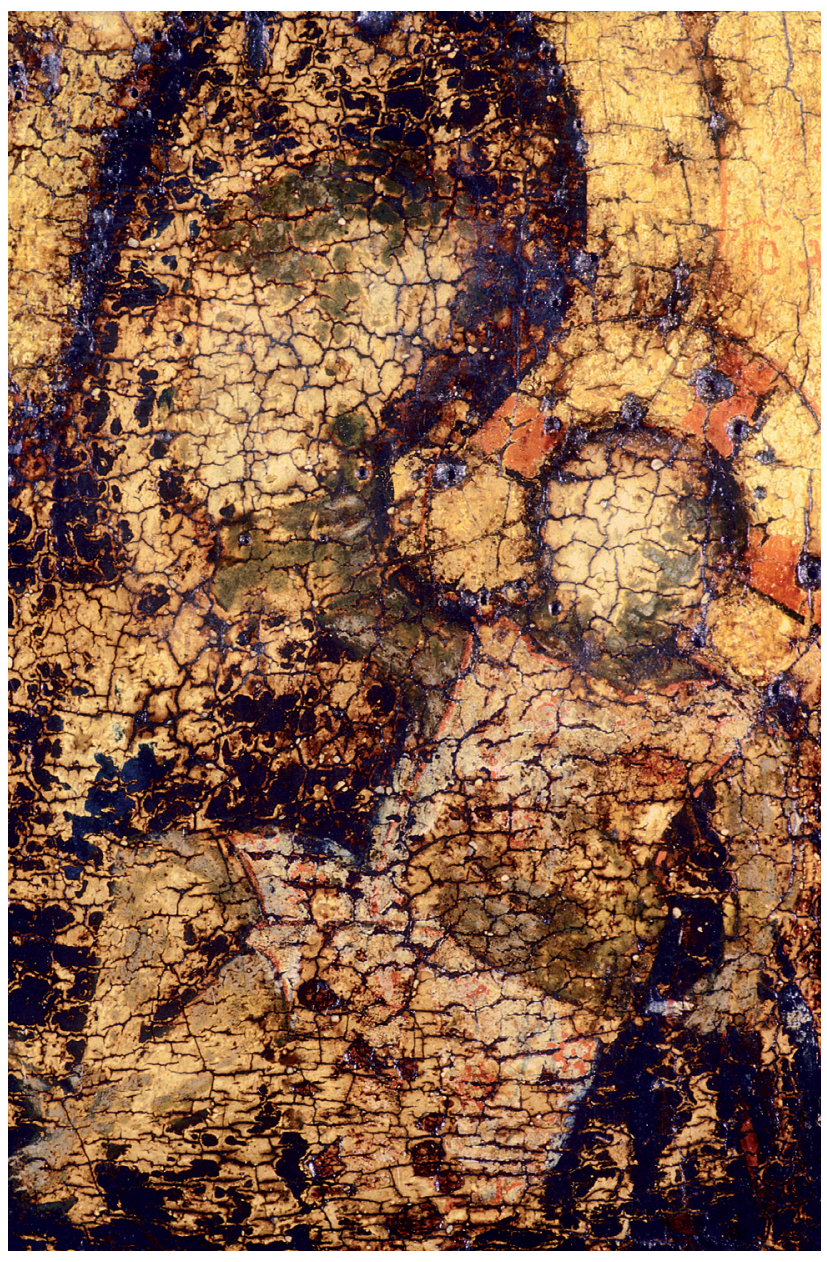

Fig. 7. Detail of the icon after cleaning and removal of the overpainting.

of black pigment it contains, but also because the layer above it is characterized by high transparency under infrared. The painted underdrawing is also recorded on individual areas such as some of the decorative motifs on Christ's tunic and the folds which fall from his knees (fig. 8). With regard to the style of the drawing, the brushstrokes are assured. There are no signs of incised lines on any of the figures, with the exception of the two haloes, which each have a single incised line made with a compass point. This leads us to conclude that the painter used a drawn design, ${ }^{7}$ displaying an exceptional ability to express himself freely.

\section{Assessment of pigments}

An initial estimation of the pigments the artist used was made by recording the false colours the surface procures in 


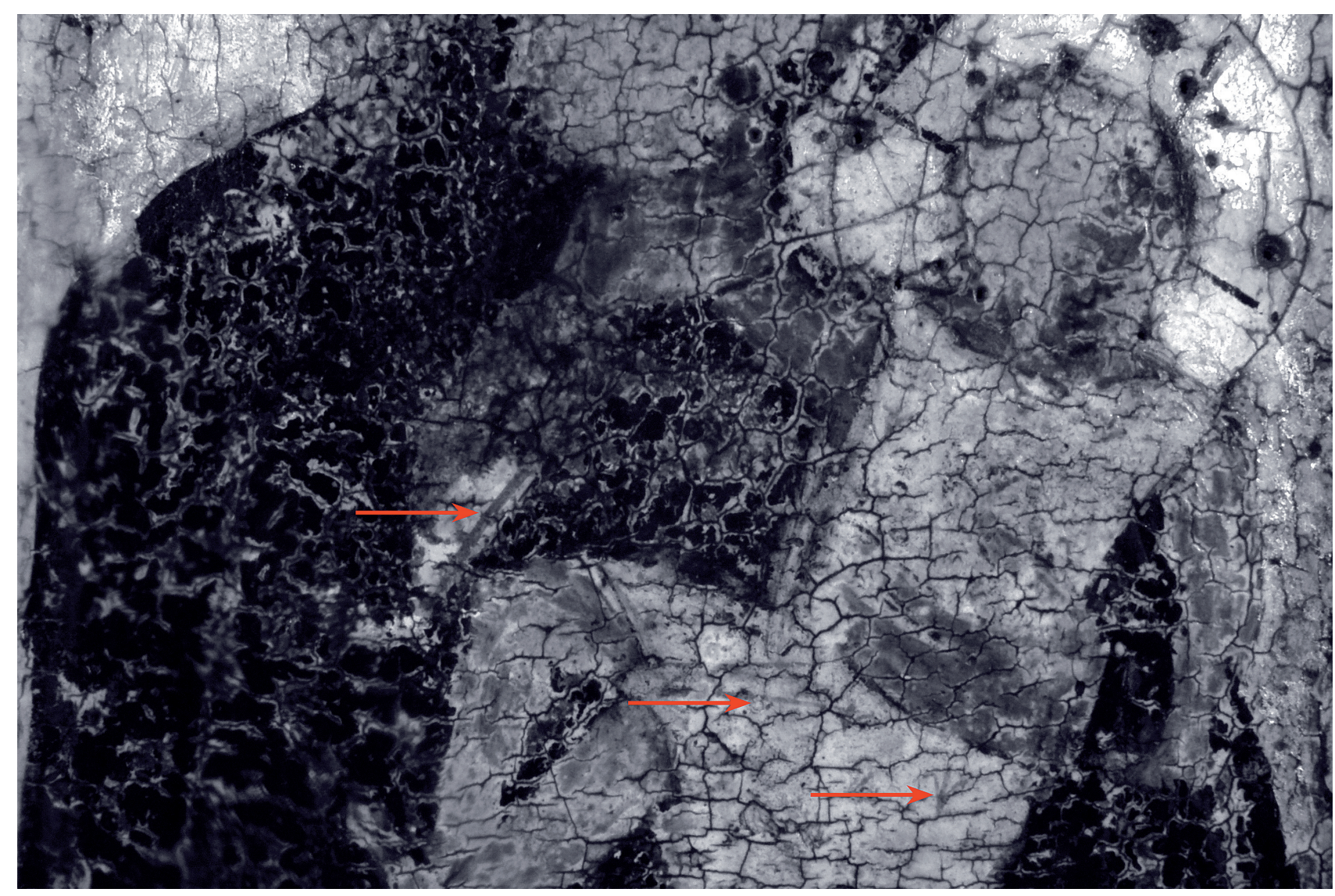

Fig. 8. Infrared reflectogram, detail of the ground showing the underdrawing.

the visible - infrared range of the spectrum: lead white, carbon black, haematite, cinnabar, red lake, natural ultramarine, indigo, and green earth. Cinnabar was used to paint the areas which render a bright yellow false colour, such as the cross-arms and the outlines of the haloes, the outline of and the decorative motifs on Christ's tunic, the mid-tones, especially on the left side of the Virgin's maphorion, and moreover, though these are later, on the abbreviated inscriptions and the band on the frame (figs 9 and 10). The areas which render a bright red false colour were painted using indigo as on the surviving parts of the sleeve of the Virgin's robe and her wimple (see fig. 10). The low absorption of the Virgin's robe in the infrared leads us to the same conclusion. The mixture of pigments in the outline around Christ's head contains natural ultramarine, which is also found in the Virgin's purple maphorion. These areas register in colour infrared images as passages of dark red.

\section{Observation of the paint surface through a stereomicroscope}

After removing overpainting and the oxidized natural resin, the paint surface was examined with a stereomicroscope in order to study the technique using magnifications ranging from $10 \mathrm{x}$ to $100 \mathrm{x}$. The damage to the work covered two thirds of the paint surface, so the overall impression of the icon was substantially altered (see fig. 7).

Nevertheless, the result was quite painterly. This characteristic, combined with the absence of harsh lines in the flesh parts and the use of a thin top layer of green earth to unify the tones, attests to the fact that the artist was interested in achieving a harmonious result. The choice of this technique gives an impression of volume, while the intensity of the bright tones are reduced by using a glaze (fig. 11). ${ }^{8}$ On the flesh parts an underlayer of orange-brown paint is used under the olive green underpaint, ${ }^{9}$ which is then largely covered by two salmon pink mid-tones (see fig. 16, part A). Finally, 


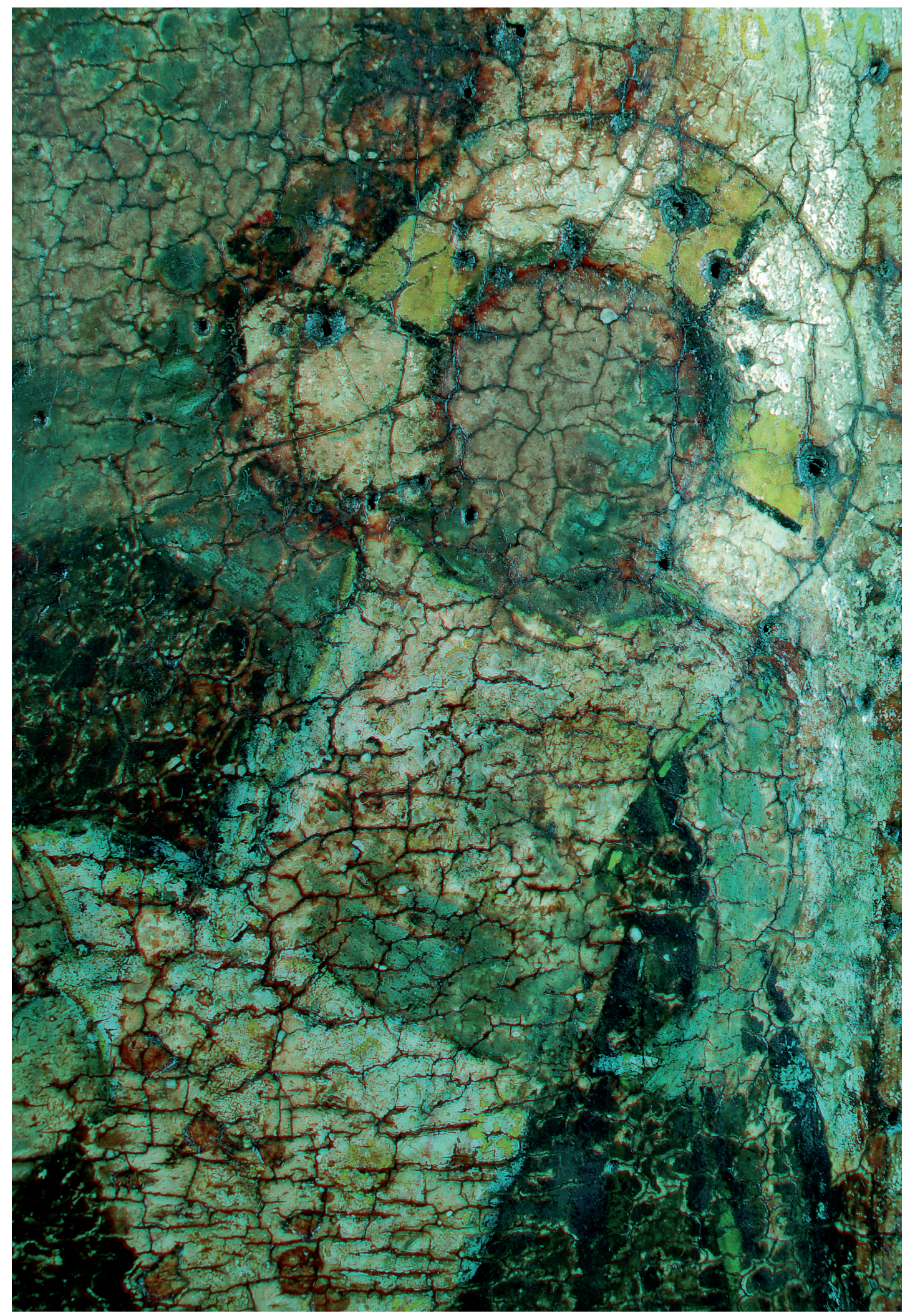

Fig. 9. False colour recording. The outline and the decorative motifs on the Christ Child's tunic, the cross arms of the halo and the mid-tones on the left side of the Virgin's maphorion procure a yellow false colour. 


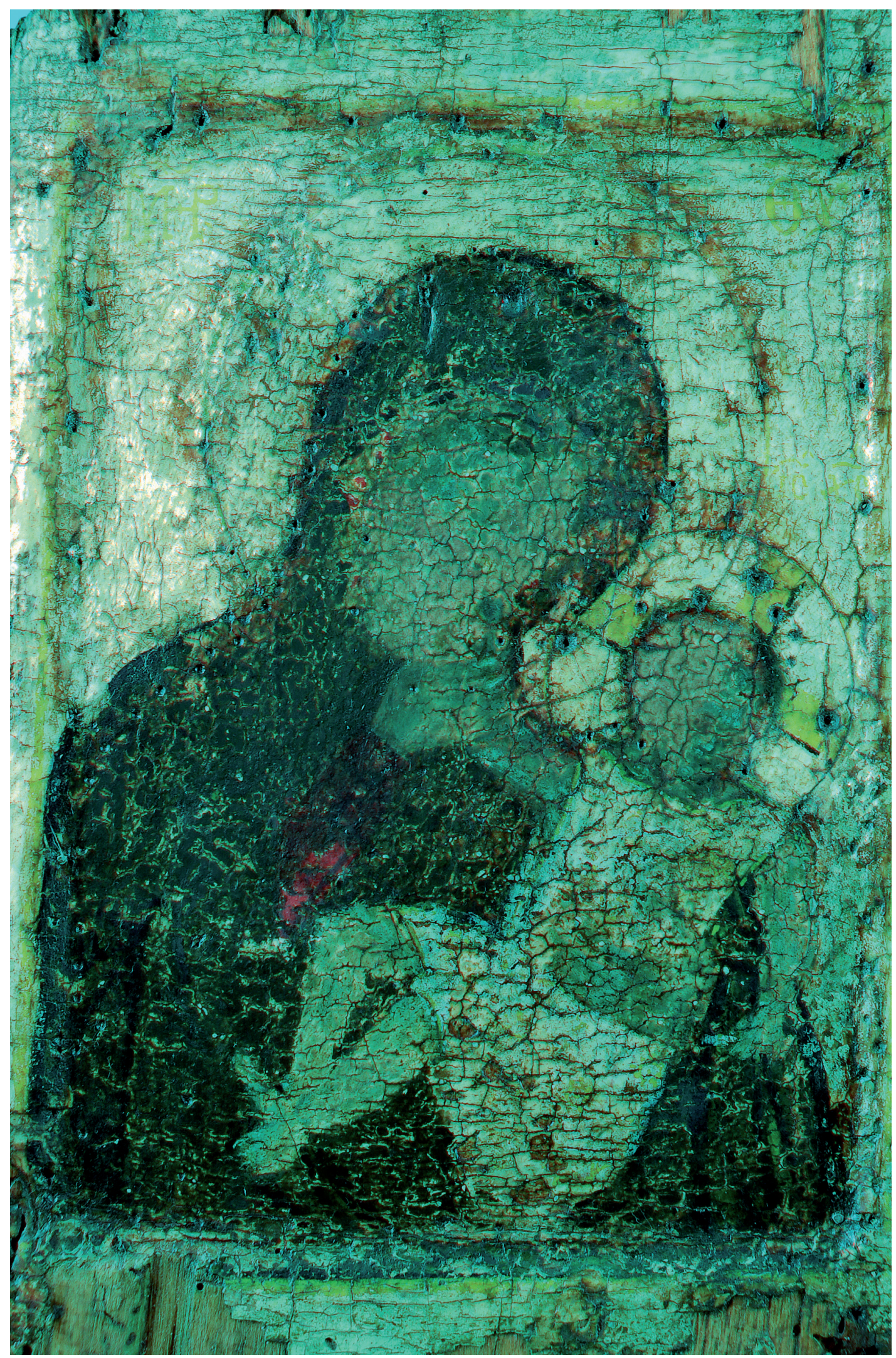

Fig. 10. False colour image giving an indication of the various pigments used. 


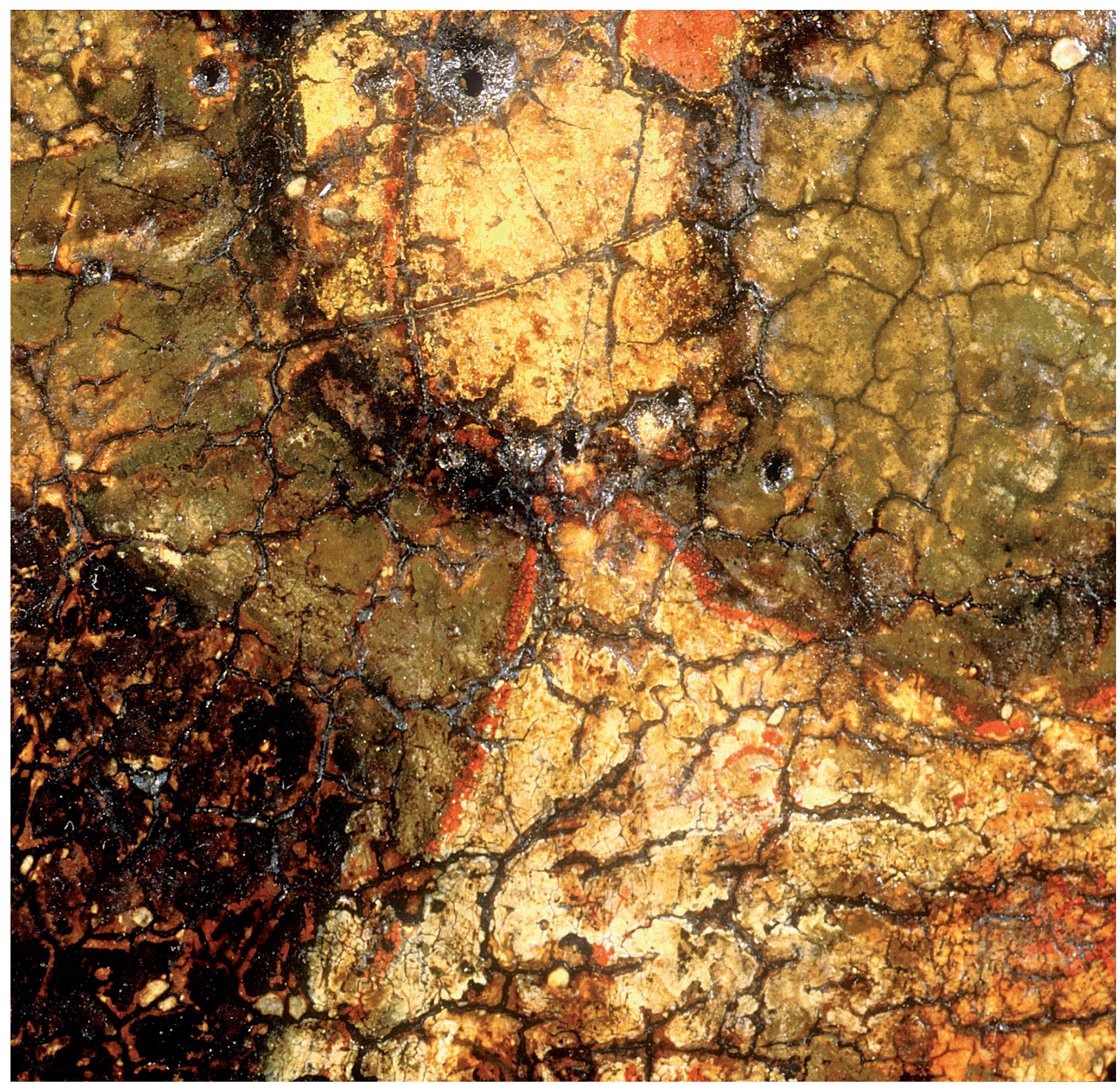

Fig. 11. Detail from the right arm of Christ. The use of a thin surface layer which unifies the tones ensures the absence of harsh lines on the flesh parts. 


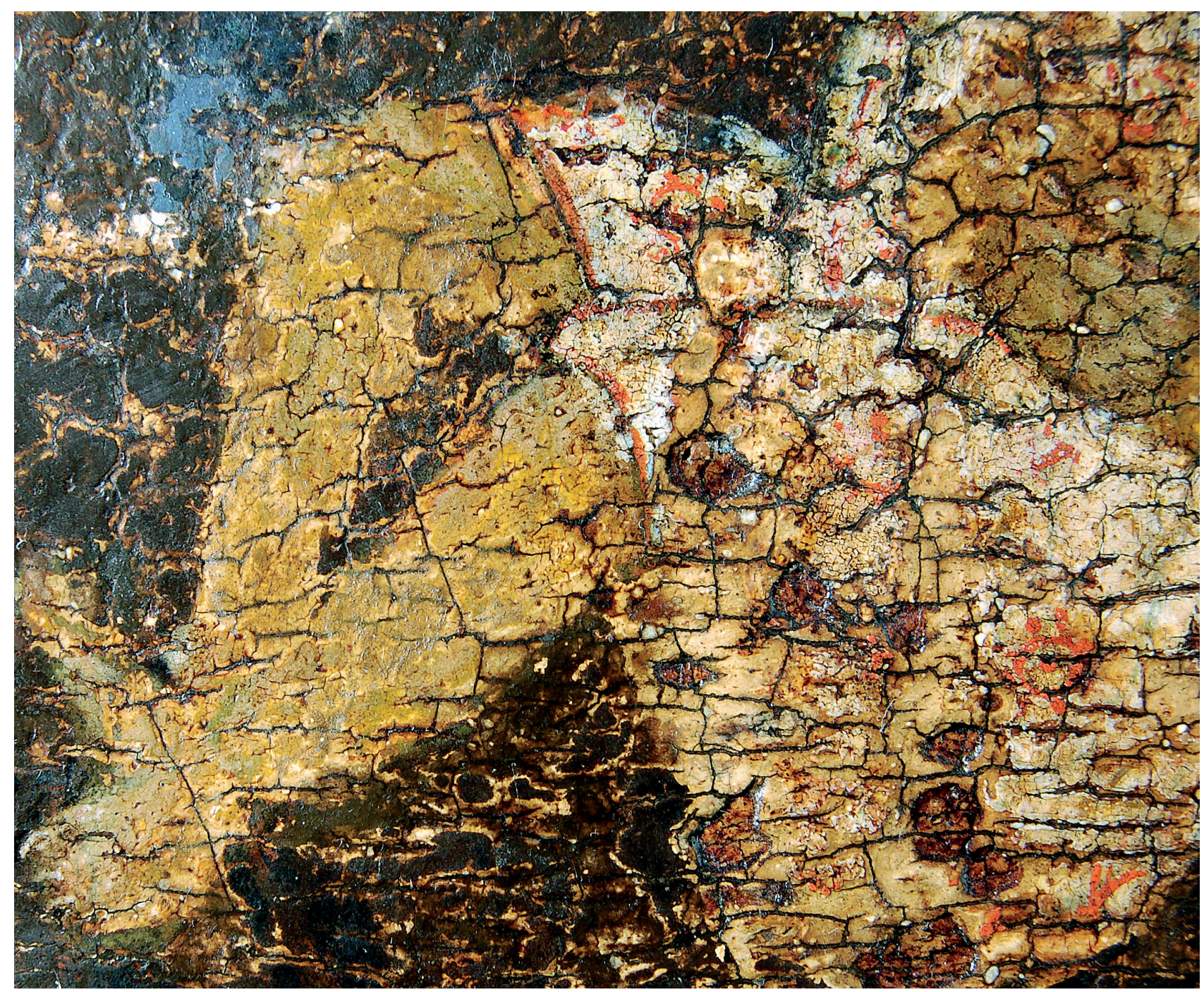

Fig. 12. Detail showing Christ's legs and the Virgin's left hand. For the flesh parts, an olive green underpaint and two bright pink mid-tones have been used. The final green layer of glaze gives the yellowish white tint.

the flesh parts are given a yellowish white cast by adding a final layer of green glaze ${ }^{10}$ (fig. 12). Given the extent of the damage to the work, as noted above, it is impossible to describe the facial features of the Virgin. The only features which can be picked out are the eyebrows, which are brown, arched and do not meet in the middle. Because they are situated quite high up, a very narrow forehead is created. Despite the damage evident on the round face of the Christ Child, his naturalistic rendering is due in part to the large forehead, the short, round nose, the narrow chin, the olive green underpaint and the yellow ochre highlights painted on projecting features to give a sense of volume. Around the outline of the neck some very fine shading, made using green earth, can be discerned. The same pigment, applied over the flesh parts, is also used to create shadows under the nose, the lips and the chin (fig. 13).

On the Virgin's maphorion the mid-tones are rendered in two shades of brick red, very close in hue, which are mixtures of cinnabar, haematite and red lake ${ }^{11}$ and are applied over the purple underpaint. It is worth noting that the artist uses lake over the drapery folds of the Virgin's maphorion ${ }^{12}$ as a final layer which covers the mid-tones leading to a harmonious blending of bright and dark surfaces. This technique was not common in the period to which the work is dated. 


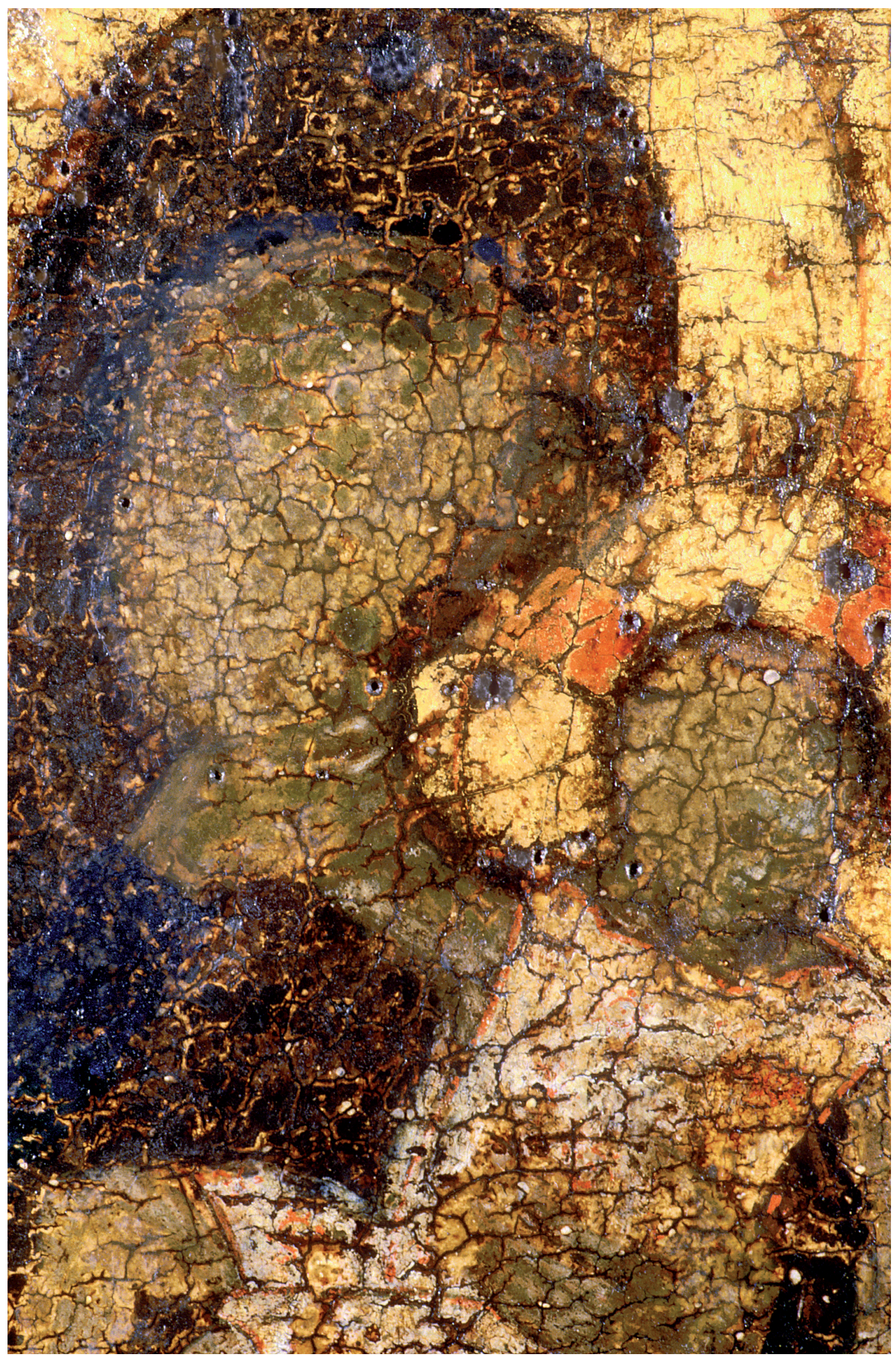

Fig. 13. Detail of the faces showing the Virgin's eyebrows and the Christ Child's facial features. 


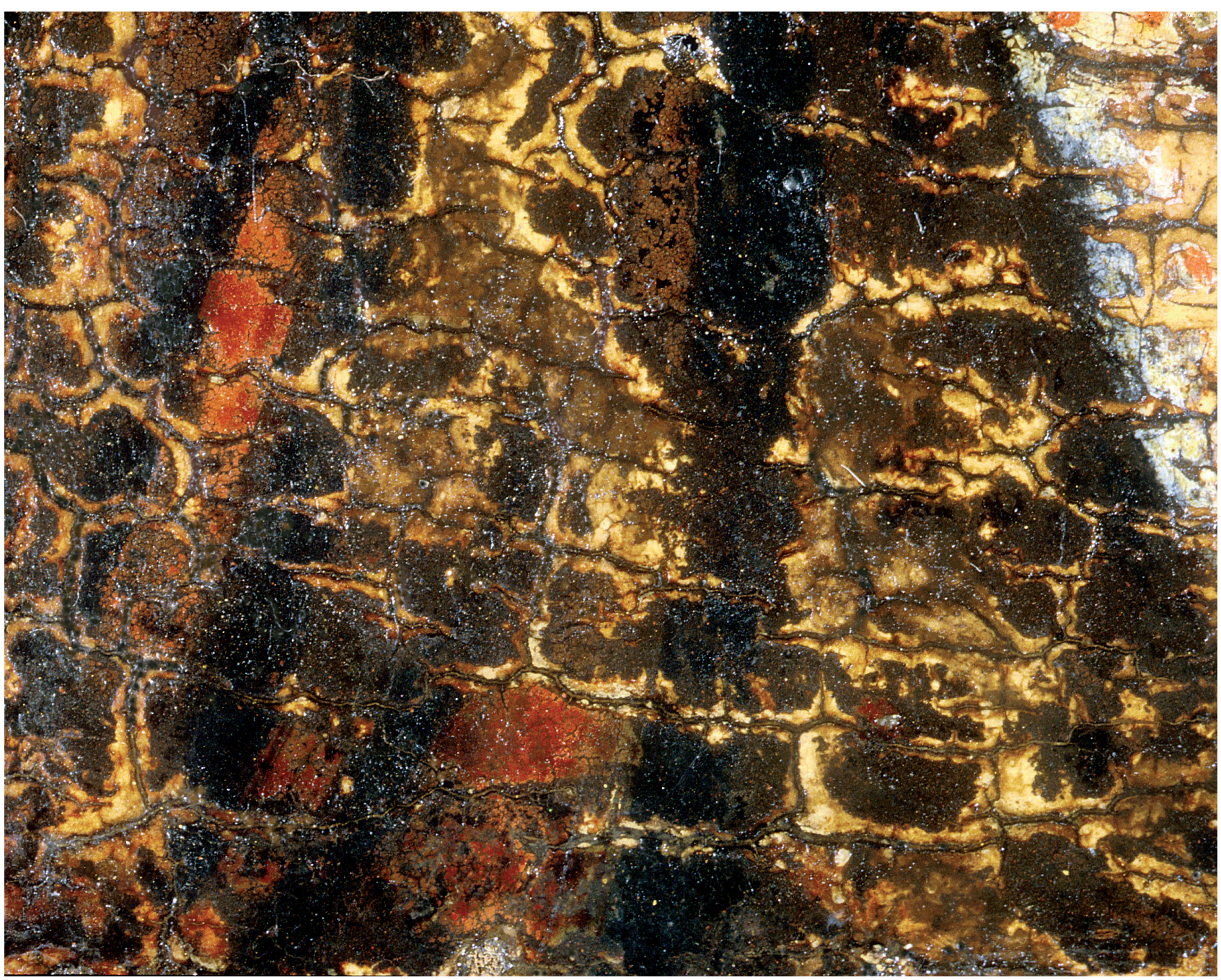

Fig. 14. Detail from the Virgin's maphorion. Traces of lake, used as a final layer above the mid-tones for a smooth gradation of light and dark passages, have been detected.

In this manner the artist achieves a particularly light shade of purple, something which could not have been done using cinnabar alone. This choice seems to have been deliberate so as to give brilliance to the Virgin's maphorion. The drapery folds are painted using a blue-black tone and are executed in long, thick lines, flanked by the mid-tones (fig. 14).

A similar technique has been used on the sleeve of the Virgin's robe, where the blue pigment is covered by a thin, translucent layer of dull green-coloured glaze. ${ }^{13}$ The fact that an orange ochre layer, in which red ochre is predominant, is found under the blue pigment is particularly interesting (see fig. 18). The blue wimple is just visible. It is rendered with two blue shades, a darker and a lighter one, and is edged with white brushstrokes.

Christ's off-white tunic is rendered in successive colour layers. Semi-translucent layers of different hues are laid one over another, ending in a final layer of pure white. In some areas the decorative red line on the edge of the tunic and some of the red motifs are covered with a layer of white. By highlighting in this way the artist may have been trying to give more volume to Christ's draperies. The shadows in the folds of his draperies are picked out using fine, very fluid and supple, green brushstrokes, of which only traces remain (see figs 12, 19).

Using glazes as the final paint layers the artist balances the hues in the flesh parts and the draperies and displays an 
intensely painterly sensitivity. The painting technique on the Virgin's maphorion and robe and on the flesh and the tunic of the Christ Child is striking. It is not just a matter of the choice of pigments and the structure of the paint layers, but the particular way in which they have been applied, by which the painter achieves a harmonious overall colour effect. The impression of three-dimensionality created by the use of highlights is reminiscent of the Fayum portraits and the encaustic icons from St Catherine's Monastery in Sinai, despite there being no recorded technological evidence for the intervening centuries.

The technical examination of the icon established that the background ${ }^{14}$ was originally painted with a single layer of yellow orpiment, whereas, in order to distinguish them from the background, the haloes were given two successive paint layers. They consist of a layer of orpiment in small particles and a surface layer containing red ochre, haematite and lead white. The latter has an off-white hue to the naked eye and was only detected in a few places.

The background preserves only traces of pigment, which is best preserved inside the two haloes. The Christ Child has a cruciform halo with red cross-arms and a fine black line at the right, painted directly onto the off-white layer (see fig. 7). It is possible that the two silver haloes are earlier than the other parts of the silver revetment, which would explain the fact that the off-white paint surface underneath them is better preserved than any other parts of the background.

\section{Examination of the cross-sections}

Sampling was carried out using a stereo-microscope and cross-sections were prepared, examined and photographed using an optical microscope at magnifications ranging from $100 \mathrm{x}$ to $500 \mathrm{x}$. The pigments were identified by SEM-EDX.15

In the samples analysed the following pigments were identified: lead white, carbon black, haematite, cinnabar, red lake, ultramarine, indigo, ochre, orpiment and green earth, as well as chalk and quartz particles used as admixtures, in the paint layers and the ground.

This was a popular and widespread palette in the thirteenth century. A similar range of pigments has been found in other thirteenth-century works, as have chalk and quartz particles, both in the ground and in the paint layers. ${ }^{16}$

The examination of the cross-sections, led to a better un- derstanding of the artist's working method regarding the use of successive paint layers and the pigment mixtures. The description of the paint layers follows the order in which the artist worked, i.e. from the bottom layer to the top.

\section{Ground (fig. 15)}

Analysis of the ground showed that it was mainly made up of gesso and a small quantity of chalk (calcium carbonate). ${ }^{17}$ The peaks of silicon $(\mathrm{Si})$ and oxygen $\left(\mathrm{O}_{2}\right)$ recorded are due to the presence of large, whiteish crystals of mineral quartz $^{18}$. Examination under an optical microscope led to the identification of the milky-coloured, opaque particles of quartz, which look like white clouds.

\section{Hand of the Christ Child (fig. 16)}

The first, orange-brown, layer is tightly packed, made up of fine particles. It is uneven in thickness and consists mainly of red ochre and haematite. It seems likely that the artist used it as an underlayer in order to give intensity and depth to the olive green underpaint above it. ${ }^{19}$ Then comes the second layer of underpaint, a dense layer of irregularly sized particles, mainly made up of green earth mixed with a few particles of lead white, extremely fine particles of orpiment, and some red ochre and haematite. Next there is the thin, dense layer of the mid-tone, consisting mainly of orpiment with some haematite and just a few particles of lead white, which are concentrated at the point of contact with the next layer. The artist used this mixture in order to render the flesh tones. The light pink layer of the highlights follows, which includes large particles of lead white ${ }^{20}$ mixed with a tiny amount of haematite and a scattering of cinnabar particles (fig. 16, part A). A translucent layer of green earth glaze, mixed with just a few particles of pigment (red ochre, organic black and orpiment) is found on the surface. The painter applied this thin layer to cover the underlying paint layers and give them a darker hue (fig. 16, part B).

The varying proportions of green earth to orpiment, haematite, red ochre and lead white in the underpaint and the mid-tone, is the distinguishing factor in creating the hue, in order to render the flesh tones. It was most probably a choice the artist made in order to give a more natural look to the flesh parts and make the figures more expressive.

On the flesh parts of the thirteenth-century icon of the Virgin and Child with busts of Saints (Benaki Museum, inv. no. 32650) and on the flesh parts of the Virgin and St John in the thirteenth-century phase of the Crucifixion on 


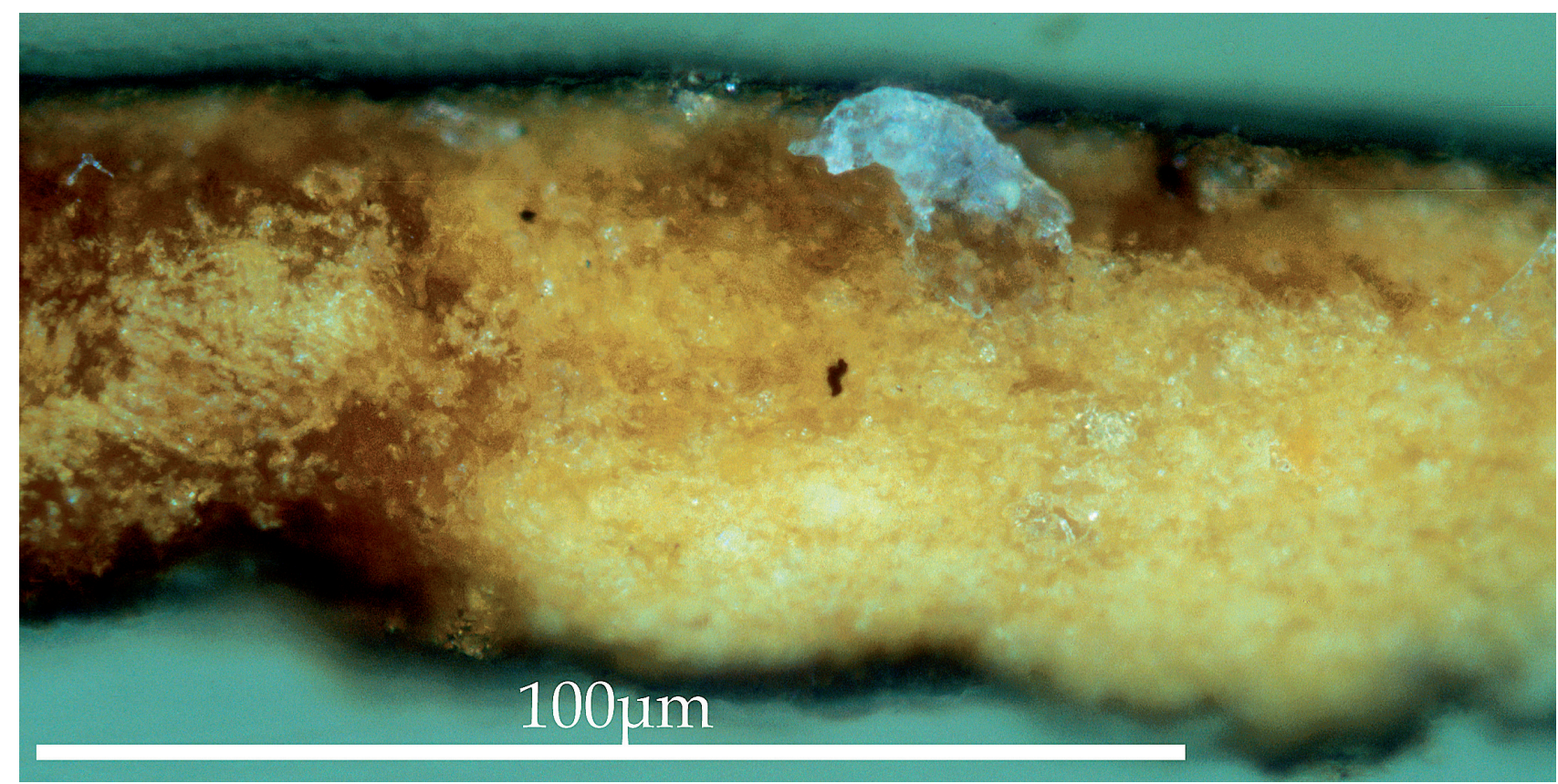

a

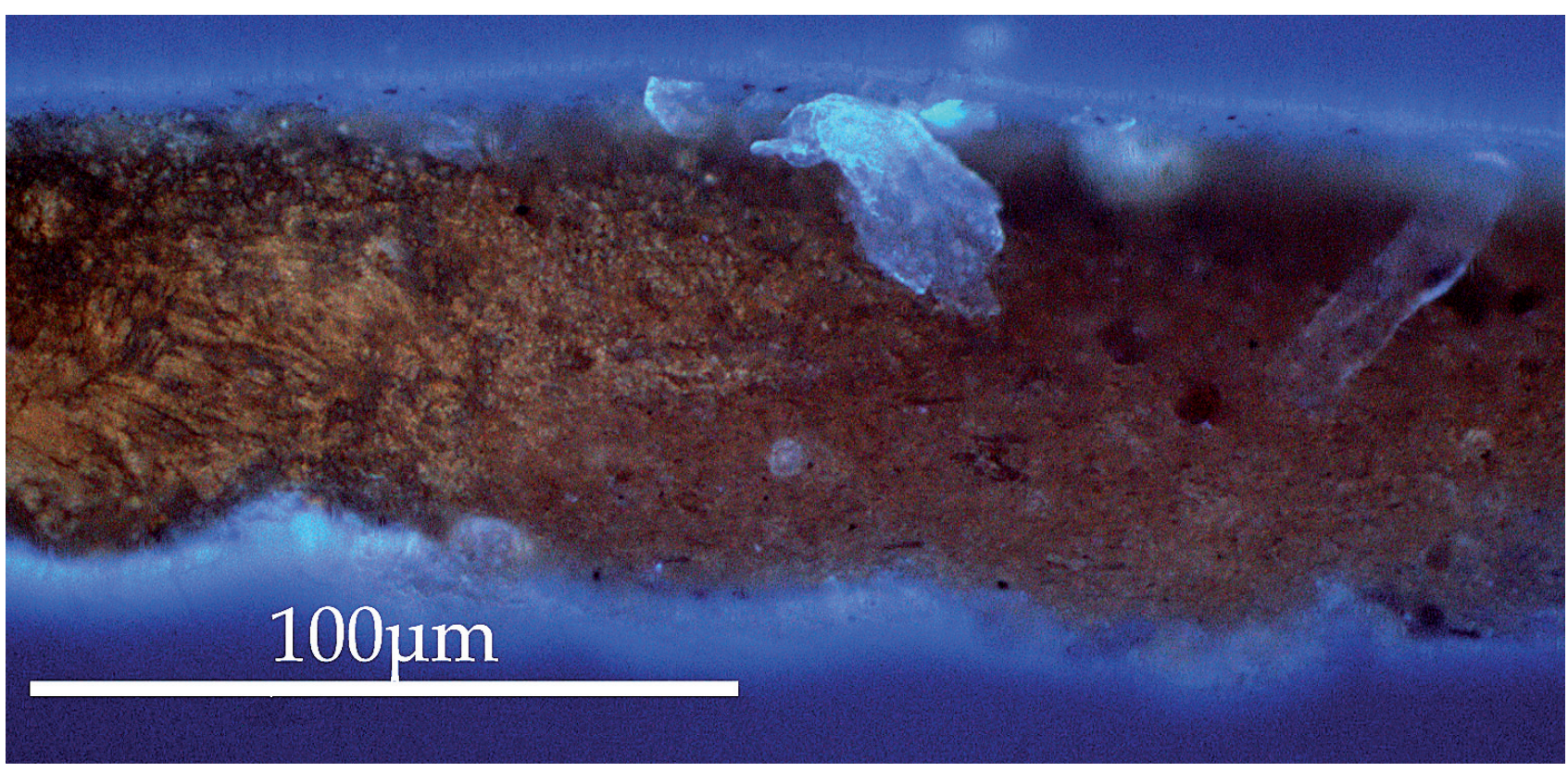

$\mathrm{b}$

Fig. 15. Ground cross-section: (a) under reflected light, (b) under UV excitation source. 


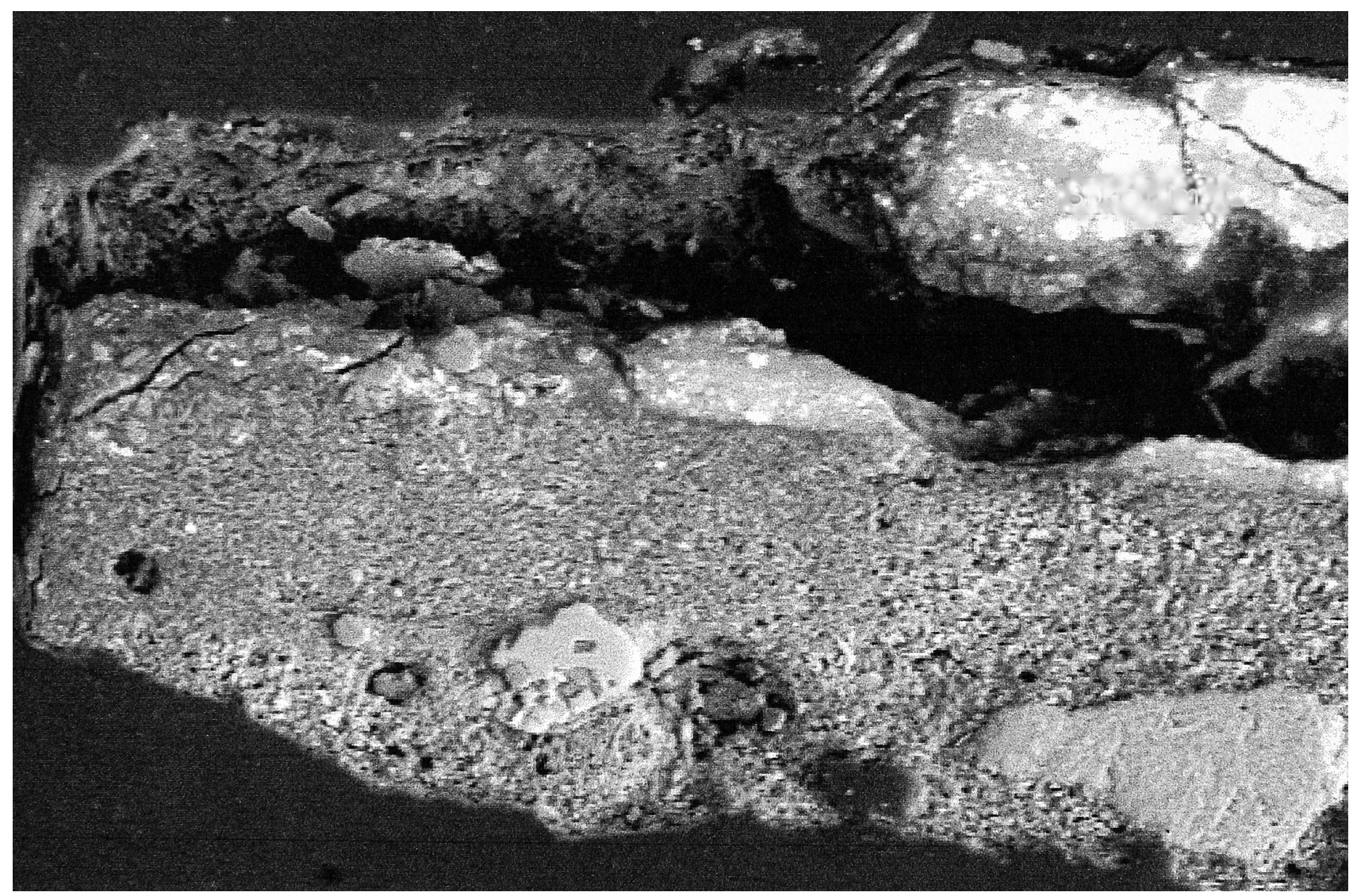

C

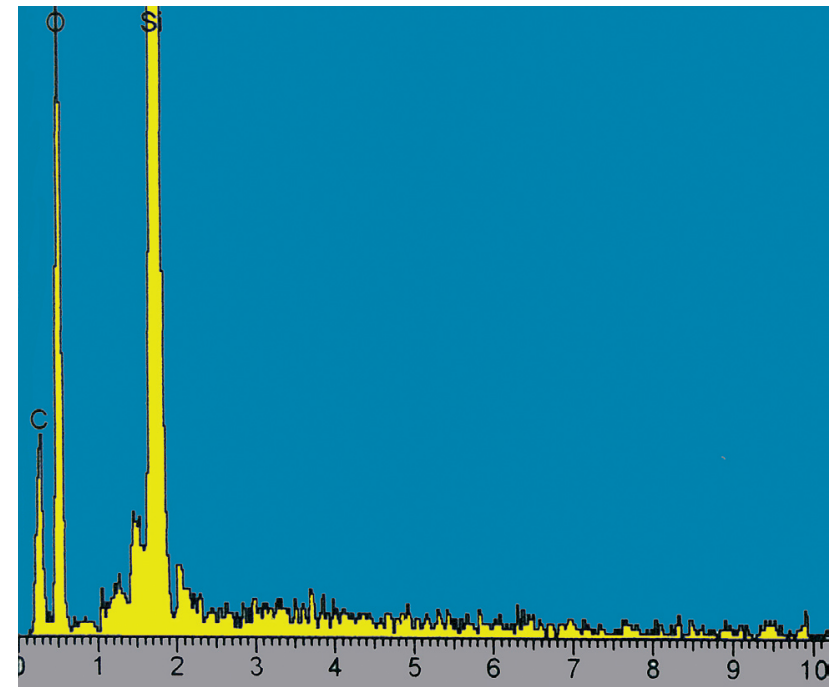

$\mathrm{d}$

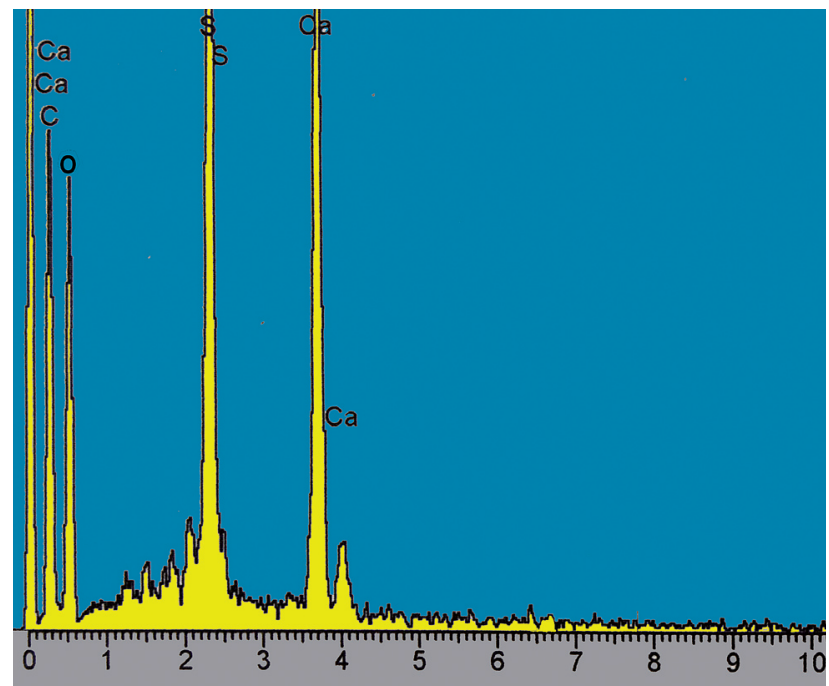

e

Fig. 15. Ground cross section: (c) S.E.M. micrograph with (d) spectra of silicon, (e) spectra of gesso. 


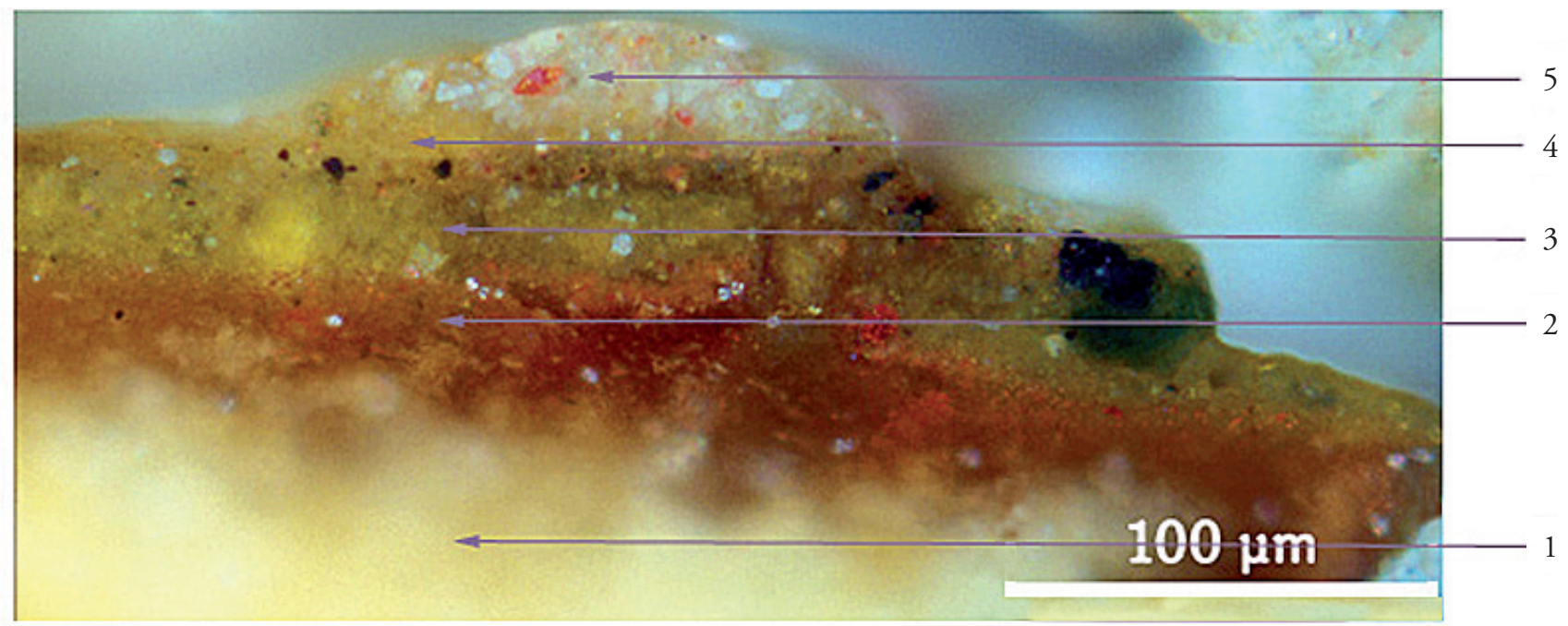

$\operatorname{Part} \mathrm{A}$

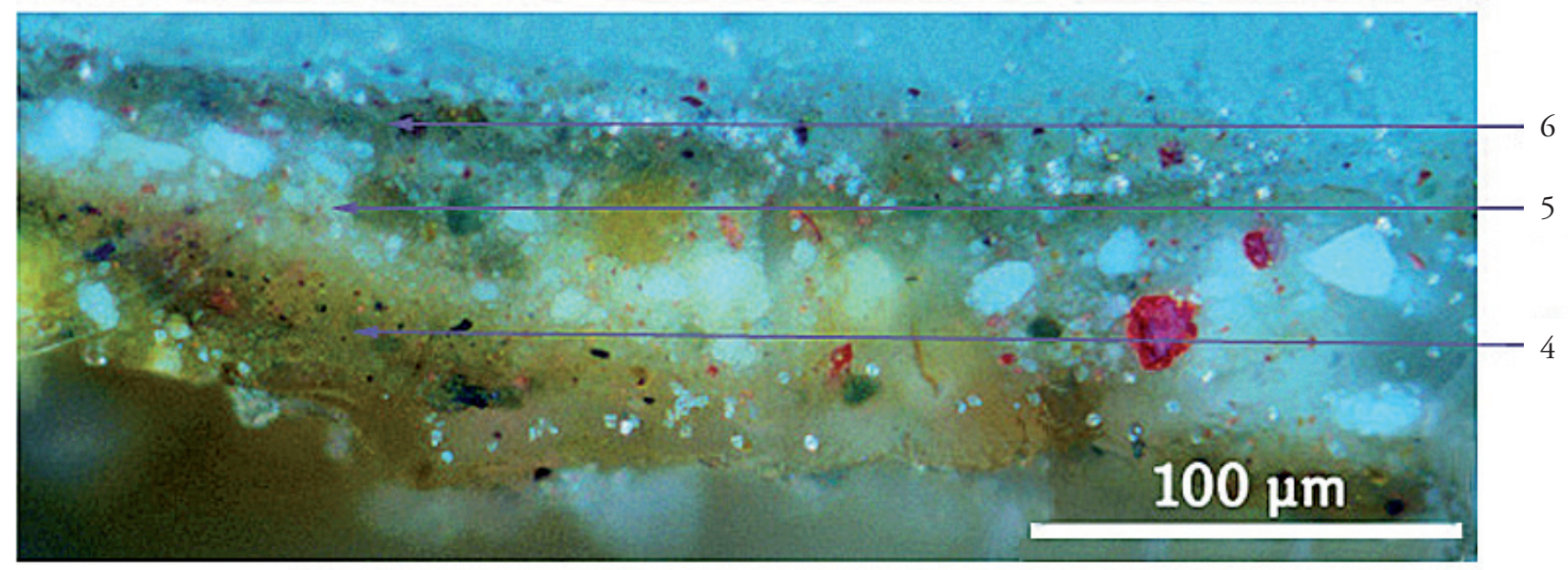

Part B

Fig. 16. Cross-sections from Christ's hand. Part A: (1) ground, (2) underlayer, (3) underpaint, (4) thin compact layer of orpiment mixed with lead white and haematite, (5) highlights. Part B: (6) translucent layer of green earth glaze.

a double-sided icon in the Athens Byzantine and Christian Museum (inv. no. T 157) a dull green underpaint has been used containing the same pigments, including orpiment, as all three painters used orpiment to give a luminous tone to the flesh. The proportions of the pigments used and the method of adding the orpiment show the special role it played in creating the overall effect of works. Another thing the paintings have in common is the translucent glaze used to cover the underlying paint layers (see n. 10).
The Virgin's maphorion (fig. 17)

The purple underpaint of the maphorion is applied in a thick layer of irregularly-sized particles, containing red ochre, haematite, a black pigment, a few particles of ultramarine, cinnabar, lead white, a few scattered particles of quartz (see n. 16) and chalk. This is an unusually large variety of pigments to be found in a single paint layer. It suggests that the painter had particular knowledge of the behaviour of pigments in order to create the desired tone. 


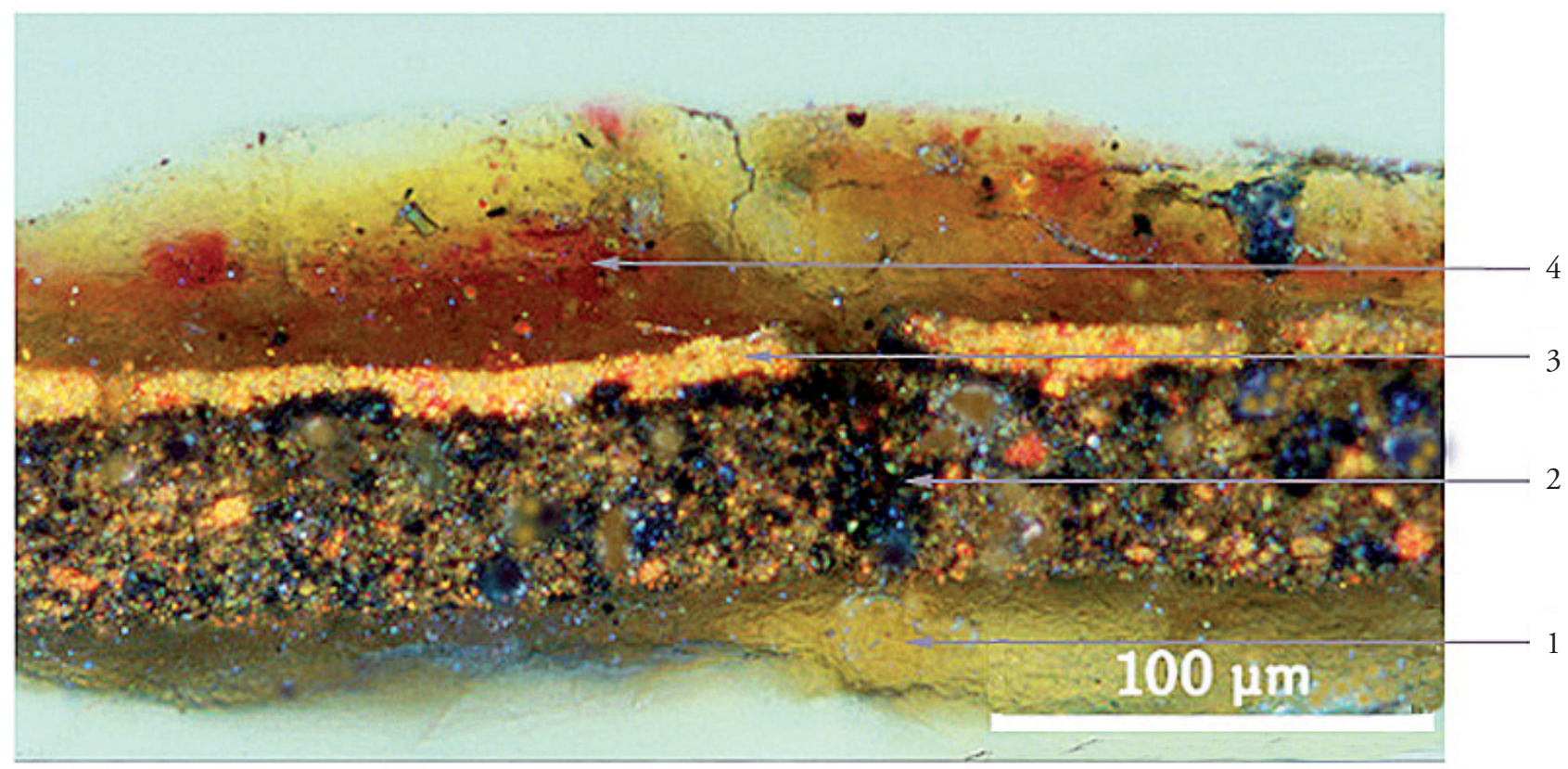

a

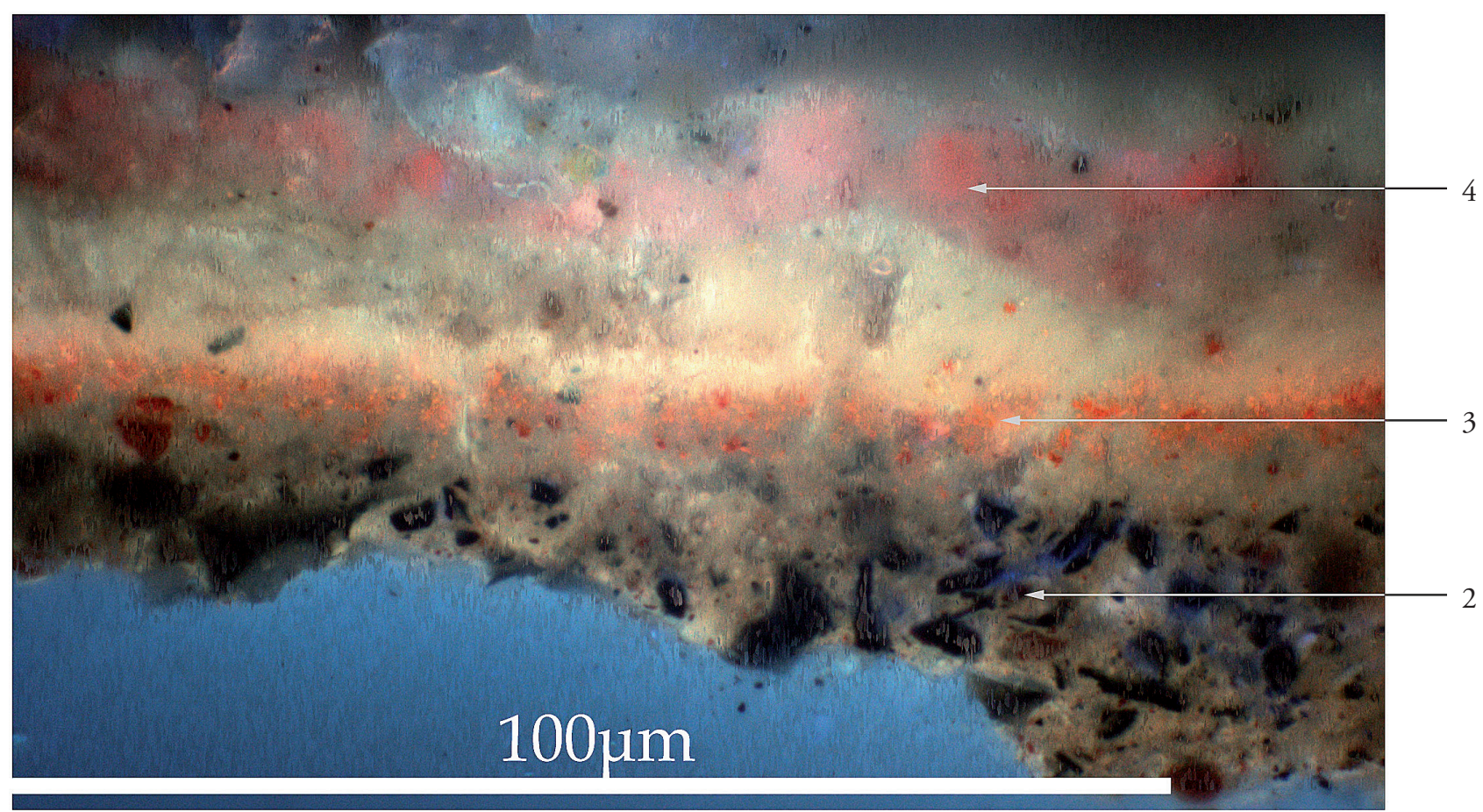

b

Fig. 17. Cross-section from the Virgin's maphorion: (a) under reflected light, (b) under UV excitation source: (1) traces of ground, (2) underpaint, thick layer of irregularly sized particles, (3) mid-tone, (4) translucent layer of glaze containing lake. Note the lakes pink hue under UV. 


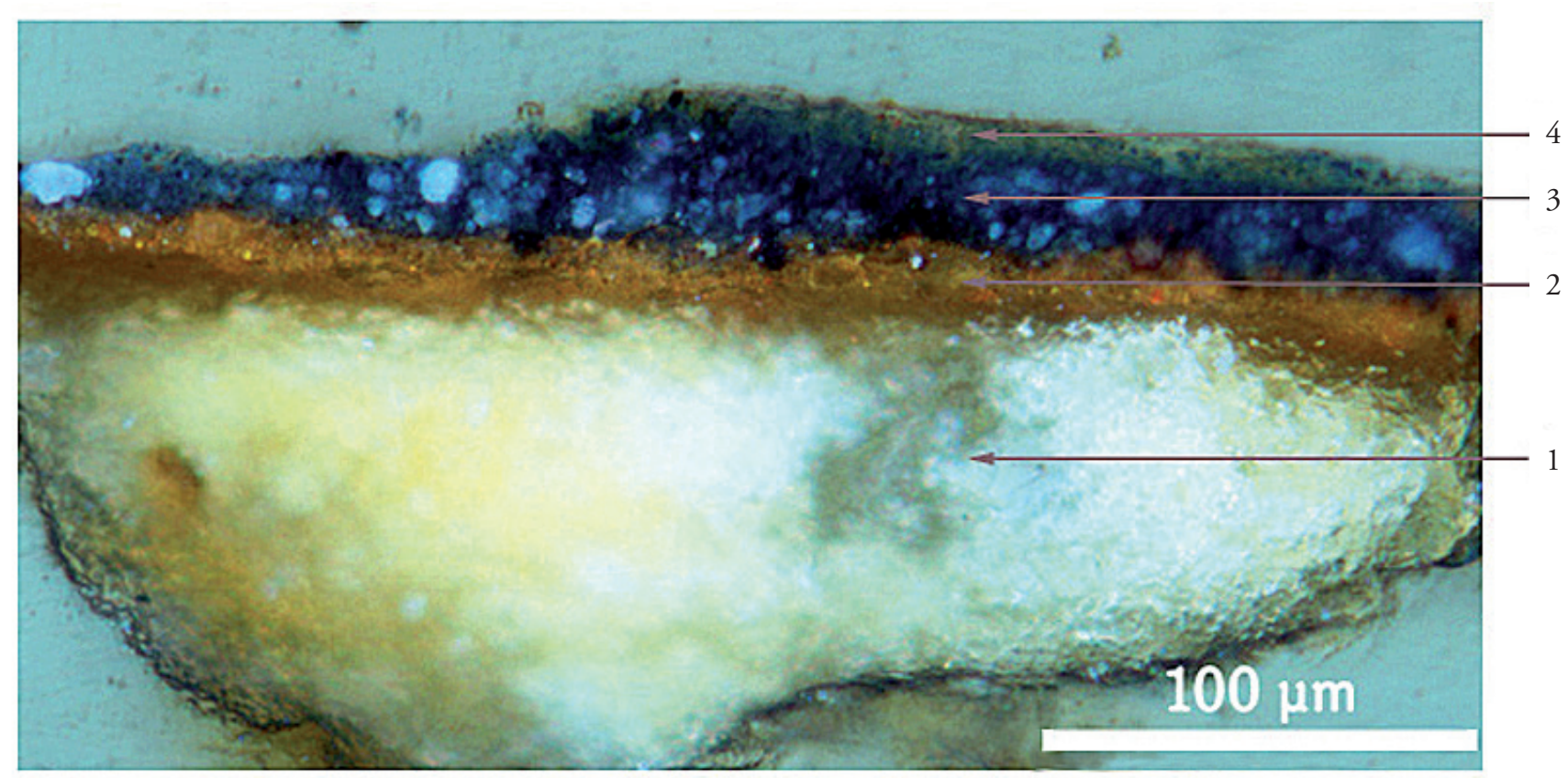

Fig. 18. Cross-section from the Virgin's robe under reflected light: (1) ground, (2) underlayer, (3) underpaint, (4) translucent layer of glaze containing green earth.

This is followed by the mid-tone, a thin layer containing red ochre, haematite, cinnabar, lead white and chalk, mainly at the point of contact with the layer above. Finally a translucent red layer of glaze containing red lake is recorded. The composition of this layer was established by electron probe microanalysis combined with examination under an optical microscope. It is a mixture of red lake, chalk and ochre (peaks of $\mathrm{Ca}$ and $\mathrm{C}$ are due to chalk while $\mathrm{Fe}, \mathrm{Al}$ and $\mathrm{Si}$ come from the ochre). It should be noted that in works dating from the fourteenth century onwards, such layers of glaze usually contain pure lake. The high degree of discoloration, or fading, of the layer is due to long-term exposure to light. ${ }^{21}$

There is a striking similarity with the underpaint in the maphorion on the thirteenth-century icon of the Virgin and Child with Busts of Saints (Benaki Museum, inv. no. 32650) and the underpaint on the phelonion of St Nicholas in the double-sided icon from a private collection, also early thirteenth century (see n. 2). The same technological feature is also found in two icons from the Byzantine and Christian Museum of Athens: in the underpaint of the maphorion of the mid-thirteenth-century Virgin Hodegetria (BCM, inv. no. T 191) and the underpaint of the Virgin's maphorion in the thirteenth-century phase of the double-sided icon of the Crucifixion (BCM, inv. no. T 157) (see n. 9).

\section{The Virgin's blue robe (fig. 18)}

In the thin, dense, bottom layer red ochre predominates, mixed with haematite, an organic black pigment and a few particles of green earth. It is found under the blue on the Virgin's sleeve and the painter used it to give a warmer hue to the upper layer. ${ }^{22}$ The use of such a technique presupposes that the next layer has restricted covering power. Then comes the underpaint for the robe, a very thick layer made up of lead white, chalk and a blue organic pigment which should probably be identified as indigo, ${ }^{23}$ due to its characteristic appearance under the metallographic microscope and the absence of copper $(\mathrm{Cu})$ or sodium $(\mathrm{Na})$ peaks in SEM/EDX analysis. The underpaint layer also contains small amounts of red ochre and haematite. Finally there is a very fine, translucent layer of greyish coloured glaze, mainly made up of green earth and red ochre. It is likely that the artist used it to mitigate the overall tone of the blue garment. 


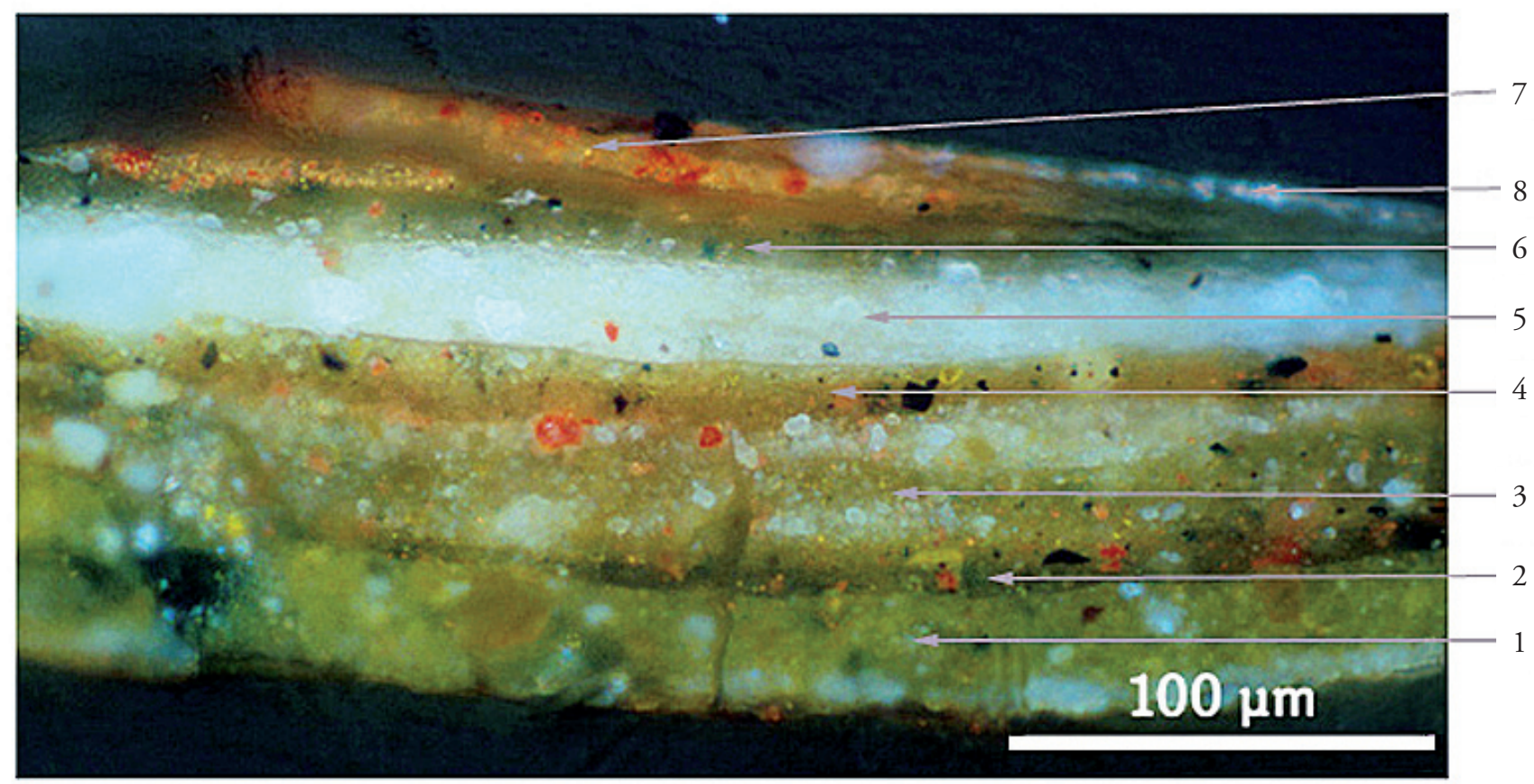

Fig. 19. Cross-section from Christ's tunic: (1) underpaint, (2) a particularly thin layer of green earth, haematite, cinnabar and black, (3-4) two successive layers, both containing lead white, haematite, red ochre, cinnabar, green earth and black pigment, (5) the off-white layer of tunic, (6) shading, (7) the decorative motif, (8) fine white brushstroke of lead white.

\section{The Christ Child's off-white tunic (figs 19, 20)}

This cross-section consists of many paint layers of irregular thickness and particle size when compared to the other samples. It is worth noting that the tunic is rendered using a total of five layers of different tones. The thick layer of underpaint contains a large amount of green earth mixed with large particles of lead white, extremely fine particles of haematite, chalk and quartz. The next layer is very thin and contains a large amount of green earth mixed with just a few particles of haematite, cinnabar and black. Then there are two successive layers containing lead white, haematite, red ochre, cinnabar, green earth and a black organic pigment. The first of these layers is thick, light in colour with quite a lot of lead white, whereas the second is thin and dark with a large scattering of black organic pigment particles. They are succeeded by the off-white layer of the tunic which is thicker than the layers beneath it and mainly contains lead white and a tiny amount of chalk. That is followed by a thin, fluid layer used for the shading, which is made up of green earth with a few particles of haematite and orpiment. Then a reddish-orange layer can be detected, which is the decorative motif. It contains a large amount of haematite in a mixture with large particles of cinnabar and a little orpiment. At the right of the cross-section a very fine white brushstroke can be discerned, consisting of lead white which partly covers the red decorative motif. ${ }^{24}$

\section{Christ's halo (fig. 21)}

A yellow layer containing a large amount of orpiment ${ }^{25}$ and traces of haematite is visible. It is followed by a very thin, dense layer of red ochre, haematite and lead white which gives the background a warm hue. On the right a very fine black layer is discernible from the cross on the Christ Child's halo. The top two layers, of bole and gold leaf, belong to a later phase.

\section{Conclusion}

Of all the technical features recorded in the study of this work the following should be noted as the most characteristic:

- the confidently executed free-hand underdrawing;

- the painter's method of using the pigments and his great skill in mixing them. As Byzantine artists did not lack 


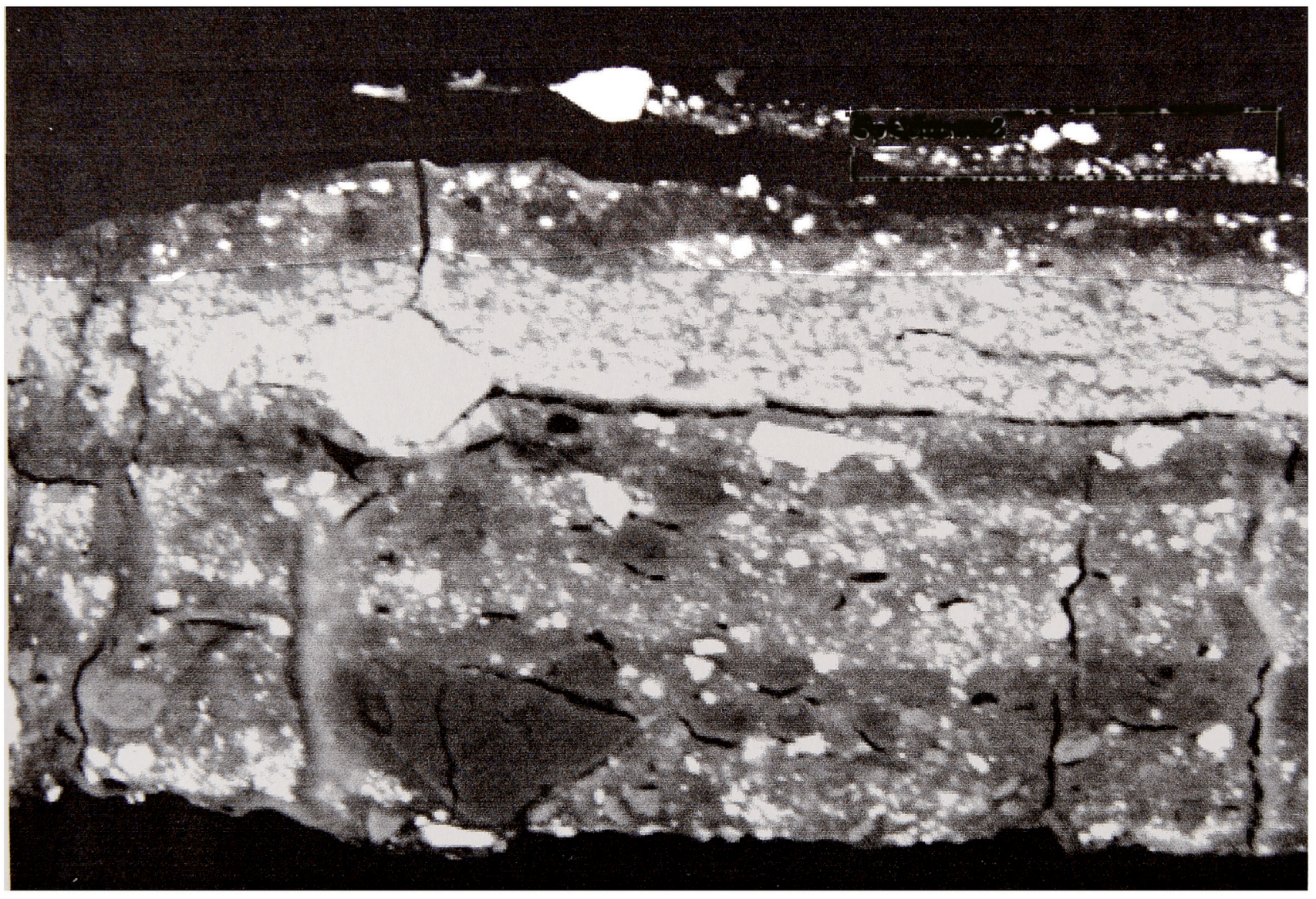

a
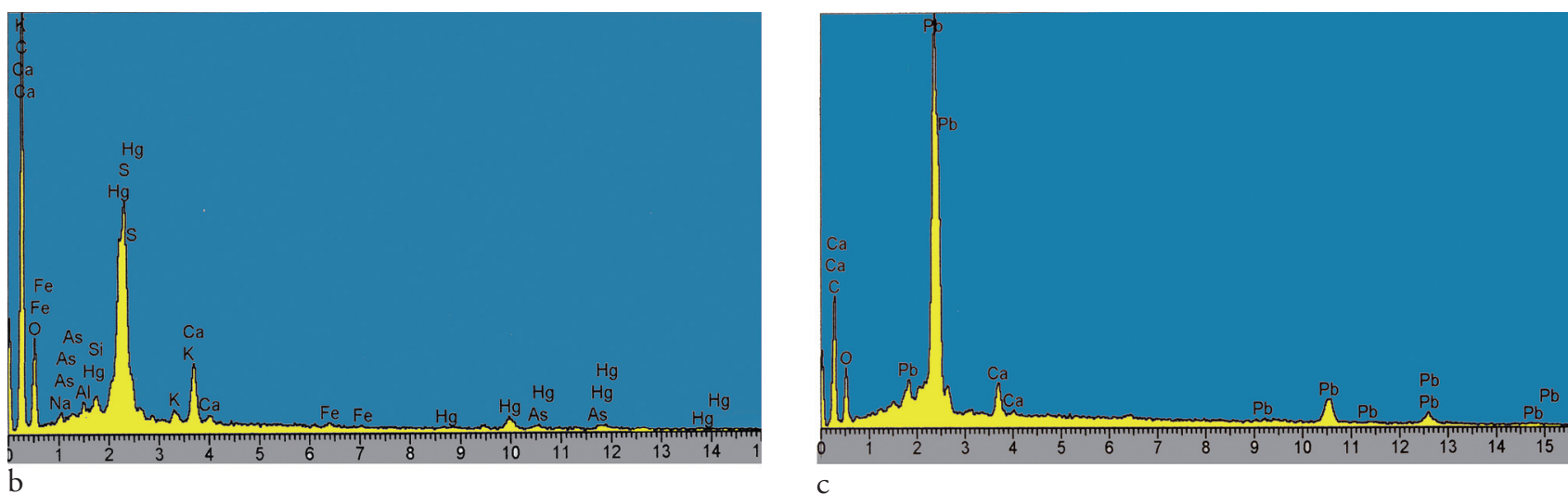

Fig. 20. Cross-section from Christ's tunic: (a) S.E.M. micrograph and spectra of (b) cinnabar and orpiment, (c) lead white and chalk. 


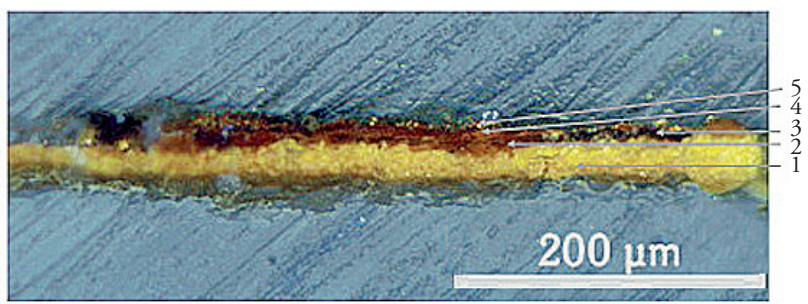

Fig. 21. Cross-section from the background: (1) yellow layer of orpiment with just a few haematite particles, (2) thin layer of red ochre and haematite, (3) thin layer of black, (4-5) bole and gold leaf (from later intervention).

technical ability, choosing to restrict the colours and the range of hues resulting from their mixture was not a matter of necessity but undoubtedly a deliberate choice;

- the use of red lake mixed with other pigments, as the top layer on the Virgin's maphorion;

- the use of a transparent, light green glaze as the final layer on the flesh parts and the Virgin's blue robe in order to unify the shades and tone down the intensity of the colours;

- the use of a double layer of underpaint in two passages of the work, both in the flesh parts and in the blue robe of the Virgin. Different colours were applied in the successive layers of the underpaint so as to give the final shade the artist wanted to achieve;

- the use of chalk and quartz particles both in the paint layer and the ground;

- the unconventional method of rendering the Christ Child's tunic using successive paint layers of irregular thickness, indicating exceptional ease and/or ability in modifying the rendering of individual passages on the spot.

This information, gleaned from the technical analysis of the icon, clearly points to a date in the thirteenth century and also helps decipher the work's identity.
Restoration

Once the icon had been examined and conserved, the final question to be addressed was that of its artistic restoration. Since each work of art is unique and presents its own particular problems, in the Icons and Easel Paintings Conservation Laboratory of the Benaki Museum the paint is retouched in accordance with the age and individual nature of the work, once the particular method and degree of intervention has been settled upon.

The high level of damage to the icon posed significant questions as to how much inpainting should be done and what restrictions should be applied. Finally it was decided to carry out a selective covering of the damaged areas on the two figures, paying less attention to the Christ Child's draperies and the ground. The method chosen for retouching paint loss was moderate use of a tone exactly matching the surrounding colour and in keeping with the overall aesthetic of the work. At this stage comparative data from other works of the same period and genre were deployed. In reconstructing the drawing and colour of the Virgin's right hand and the sleeve of her robe, the thirteenth-century icon of the Virgin and Child from the Church of the Virgin Chrysaliniotissa in Nicosia (see $\mathrm{n} .4$ above) was used for comparison, as were other well preserved parts of the Benaki icon itself.

As mentioned above, it was decided that the earlier retouching of the ground should not be removed, as the original paint layer had been completely destroyed. All the pigment mixtures were applied as glazes, ensuring the desired translucency and brilliance, in accordance with the original painting (fig. 1).

The metal revetment, completely restored in the Benaki Museum's Conservation Department is now displayed next to the icon in the museum's Byzantine galleries.
Kalypso Milanou
Senior Conservator, Icons and Easel Paintings
Conservation Laboratory
Conservation Department - Benaki Museum
milanou@benaki.gr 


\section{Notes}

1. The icon was conserved in the Benaki Museum Easel Paintings and Icons Conservation Laboratory in 1998 by the author while the metal revetment was conserved by Depi Kotzamani in the Metal and Glass Conservation Laboratory.

2. The conservation process was first published in K. Milanou, Benaki Museum research program. Pigment analysis and other scientific methods on three icons dating from the 13th century, ICON conservation network: Exchange of technics and critical comparison between traditional and modern practiced in different countries (Vicenza, Athens 2001).

3. Other icons with metal revetments have survived from the 12th and 13th c., for example: The Archangel Gabriel of the Annunciation (no. 47) and the Virgin Annunciate (no. 48), 1108-1120 from Ochrid (Virgin Perivleptos) and the doublesided icon of the Hodegetria and the Crucifixion (no. 67), third quarter of the 13th c., also from the Virgin Perivleptos in Ochrid,

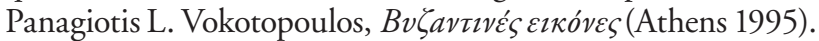

4. The icon has a similar iconography to that of the 13th-c. Virgin and Child from the Church of the Virgin Chrysaliniotissa in Nicosia, which was used to help reconstruct the Benaki

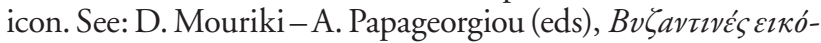

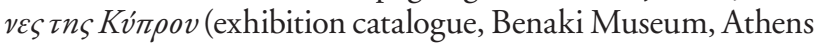
1976) no.19 (A. Papageorgiou).

5. Some examples of icons which have been subject to interventions at various periods are: the 9th-c. double-sided icon of the Crucifixion (BCM, inv. no. T 157), on which the ground was restored in the 10th c. and the figures of the Virgin and St John and parts of the Crucified Christ were retouched in

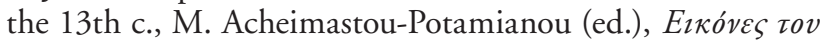

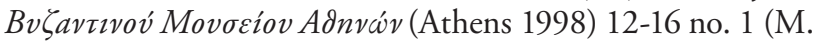
Acheimastou-Potamianou); M. Vassilaki (ed.), Mńtn $\Theta \varepsilon o v$,

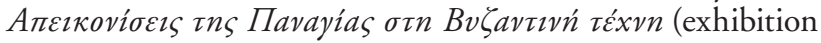
catalogue, Benaki Museum, Athens 2000) 486-87 no. 84 (C.$\mathrm{Ph}$. Kalafati). There are also 12 th-c. works which have been overpainted with the same subject in the 14 th c., and also in the Post-Byzantine period. For example, the 12th-c. Crucifixion on the main face of the two-sided icon of the Crucifixion/Mother and Child (Benaki Museum, inv. no. 3038) was repainted in the 14 th c. and the reverse in the 17 th c ; the 13th-c. icon of the Virgin and Child with Busts of Saints (Benaki Museum, inv. no.

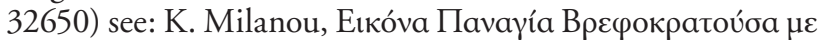

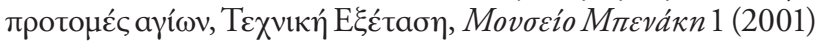
41-58. Mention should also be made of the 14th-c. icon of the Virgin and Child/Three Hierarchs (BCM, inv. no. T 1031), see: Acheimastou-Potamianou (ibid.) 40-43 no. 9 (Acheimastou-Potamianou). The 14th-c. two-sided icon with the Virgin and Child on the main face and the Akra Tapeinosi (Man of Sorrows) on the reverse, belonging to the Municipal Art Gallery of Thessaloniki, which has been restored at various periods, A.

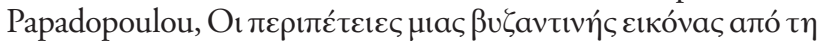

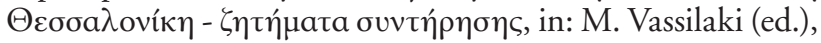
Byzantine Icons, Art, Technique and Technology, International Symposium (Irakleio 2002) 191-200. And four busts of apostles were added to the Benaki Museum 14th-c. icon of the Virgin Glykophilousa to cover damaged areas, K. Milanou, Eıкóva ıๆৎ

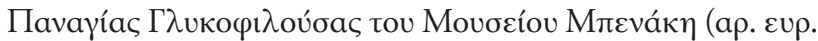

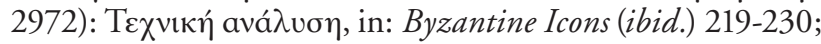
K. Milanou, The Icon of the Virgin and Child and Scenes from Christ's Life with Apostles, in: I. Bentchev-E. Haustein-Bartsch (eds), Ikonen, Restaurierung und Naturwissenschaftliche Erforschung, Beiträge des internationalen Kolloquiums Recklinghausen 1994 (München 1997) 58-70. Two interventions were found to have taken place (1st phase in the 17 th c. and 2 nd phase in the 18th) on the icon of the Virgin Hodegetria of the first quarter of the 14th c in the Church of St Demetrios, in Athyto, and on the double-sided icon with the Virgin "of the Tower" on the obverse and the Crucifixion on the reverse from the Church of the Taxiarchs in Neo Marmara. Two phases of overpainting were found on the front, the first dating to the Post-Byzantine period and the second to the late 19th c. See I. Papangelos - A. Stratis - Sister

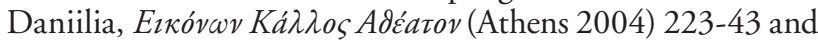
264-83 respectively.

6. Manolis Chatzedakis identified the oldest icon in the Athonite Great Lavra Monastery, an image of the Martyrs of Sebaste, Eugenios, Auxentios, Mardarios and Orestes and dated it to the reign of Alexios I Komnenos (1081-1118), which had been

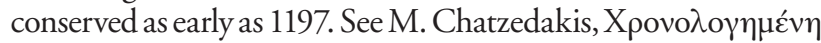

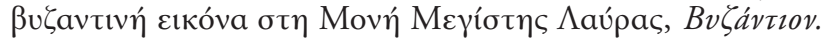

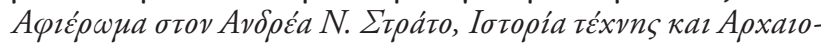

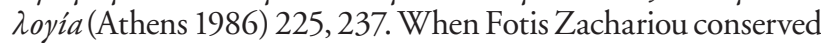
the icon in 1957, he noticed that the full-length figures of the saints had been transferred to a new support, while the ground had been covered with gold. The icon of St Panteleimon, also in the Great Lavra and dating to the early 12 th c. is a similar case. Written evidence is contained in the Typikon of the Cosmosoteira Monastery in Bera (mod. Pherres) dated 1152, in which the monastery's founder, the Sebastokrator Isaac Komnenos, provides for the conservation of important icons in the mid-12th c. The fact that he expressed this concern suggests that there was a widely known and relatively current method of conservation used for damaged works, at least in the painters' workshops of the capital, which could also have been applied in other centres, $\mathrm{M}$.

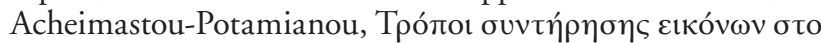
Buکávtı in Vassilaki, Byzantine Icons (n. 5) 151-61.

7. A drawn design is found on the Benaki Museum 13thc. icon of the Virgin and Child with Busts of Saints (inv. no. 32650), see: Milanou, Eıкóva Паvaүía Врєрократоúбa (n. 5) 41-58 and on the main face of the double-sided icon in the Athens Byzantine Museum from Peta in Epiros depicting the Crucifixion and the Virgin Pammakaristos (9th-, 10th-, 13th- and 16th-c. phases) on which see: Th. Chatzedakis - I. Chrysoulakis

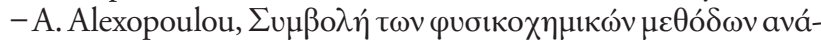

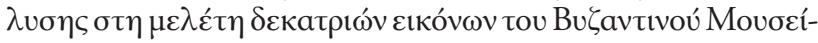
ou A $\theta \eta v \omega ́ v, \triangle X A E 4$, I $\Gamma^{\prime}$ (1985-1986) 215-45. A drawn design was also found on the double-sided icon of St Nicholas and the Virgin and Child from a private collection in Athens, dated to the mid-13th c., during an examination carried out in the Benaki Museum Conservation Laboratory by the author (see n. 2). Other examples include the icons of the Virgin Glykophilousa (Benaki Museum, inv. no. 2972), the Virgin Hodegetria from the Church of St Demetrios in Athyto (drawn design with bro- 
ken lines), and the double-sided icon of the Virgin "of the Tower" and the Crucifixion from the Church of the Taxiarchs in Neo Marmara (see n. 5). Another drawn design with broken lines is also found on the icon of Christ in Majesty from the Church of

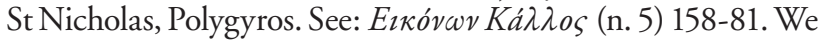
also find similar drawn designs in the 13 th c. on Western painted panels. Italian painters undoubtedly had Byzantine art in mind when they were attempting to imitate the form and the rendering of individual features. Good examples include: the early works of Giotto, Duccio di Buoninsegna and the Master of St. Francis. See D. Bomford-J. Dunkerton-D. Gordon-A. Roy-J. Kirby, Art in the Making, Italian Painting before 1400 (London 1992) 54-97 and Marco Ciatti, Some observations on panel painting technique in Tuscany from the 12th to the 13th century, in: Painting Techniques: History, Materials and Studio Practice, I.I.C., Contributions to the Dublin Congress, September 1998 (London 1998) 1-4.

8. In a glaze a much higher proportion of binding medium is used in the mixture than pigment. Thus it is very transparent and therefore achieves harmonious colour transitions and gives a particular luminosity to the overall effect.

9. The olive green tone which is used as underpaint on the flesh parts is particularly characteristic of wall-paintings of the 12th and 13th c., above all in Northern Greece. See A. Papa-

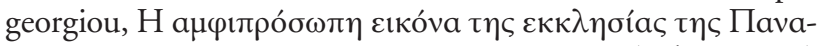

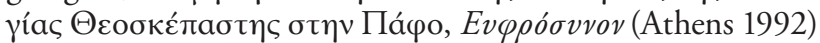
484-90. Olive green underpaint has been identified on the face of Christ in the 13th-c. phase of the Crucifixion on the doublesided icon with the Crucifixion and the Virgin and Child in the Athens Byzantine Museum and also on the flesh of the Virgin's hand in the icon of the Virgin Hodegetria (BCM, inv. no. T 191), dated to the mid-13th c. See: $\triangle X A E$ (n. 7) 238 and on the hand of the Virgin and the face of Christ in the 13th-c. icon of the Virgin and Child with Busts of Saints (Benaki Museum, inv. no. 32650) (see n. 7). Olive green underpaint was used on the flesh parts in the icon of the Virgin Hodegetria from the first half of the 14th c. (see n. 7). It is also found on Cypriot icons of the early 13th c. Examples include: the double-sided icon with the Virgin and Child on the main face and St. James the Persian on the reverse from the church of the Virgin Theoskepaste in Kato Paphos now in the Byzantine Museum of the Metropolitan

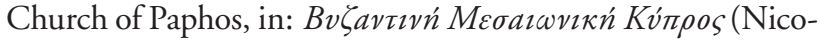
sia 1997) no. 48a- $\beta$ (A. Papageorgiou), the icon of Christ from the church of the Virgin Agros in Lemesos, in: ibid., no. 49 (A. Papageorgiou). Early 13th-c. Byzantine art was also a model for Italian artists of the same period, Mńtn $\Theta \varepsilon o v$ (n. 5) 486-87 no. 84 (C.-Ph. Kalafati). An example of a Byzantinizing icon depicting the Virgin and Child which has green shading on the flesh parts due to using olive green underpaint is the Virgin Lactans (1260-1280) in the new church of SS Cosma e Damiano in Pisa, Mńtno $\Theta \varepsilon o v ́($ n. 5) 442-43 no. 70 (M. Bacci). Green earth is also used in the underpaint on the flesh parts in works by Duccio di Buoninsegna (1278-1319) and the Master of St Francis (n. 7) and see W. Januszczak, Techniques of the World's Great Painters (London 1990) 10-17.

10. Green earth is used as the final layer on the flesh parts. It has been spread thinly, that is with a lot of binding medium and a few particles of pigment (green earth, organic black, red ochre and orpiment) in the form of a glaze to cover the layers beneath and to harmonize the tones of the paint layers, dulling their intensity. The artist's technical abilities can be seen in the way he mixes the materials he has selected to create a dark shade for the flesh parts. Because of its poor covering power green earth is often used in glazes. We find the same technique in the early 13 thc. icon of the Virgin and Child, inv. no. 32650 (n. 9), and in the flesh parts on the icon of the Virgin Glykophilousa, Milanou,

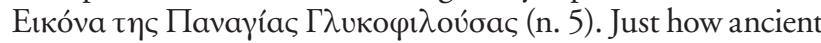
the technique is is attested by Pliny the Elder in: "On ancient Greek painting", the 35th book in his Natural History (tr. by A. Levidis, Athens 1994) 227. According to the commentary in this edition, the technique was known as far back as the Bronze

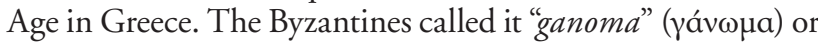
"tinning", the Italians velatura.

11. As can be shown from the evidence from historical sources the technique of preparing pigments in the form of lake was known as far back as antiquity. There are a host of references from the 8 th to the 18 th c. in recipes and recommendations to painters as to how to use them. That the ancients knew how to prepare and use lake has been confirmed by analysis. The study of pigments and binding agents in Egyptian art, mainly Fayum portraits, has shown that lake was used in Late Antiquity. Lake was found in the flesh parts of the face on one such funerary portrait of a woman in the Benaki Museum (inv. no. 6877), in a mixture containing lead white and lake: A. Alexopoulou-Agoranou-A. Kalliga - U. Kanakaki - V. Paschalis, Pigment analysis and documentation of two funerary portraits which belong to the collection of the Benaki Museum, in: M.L. Bierbrier (ed.), Portraits and Masks, burial customs in Roman Egypt (London 1997) 88-95. This had already been noted by other scholars, e.g. R.L Feller, Analysis of pigments in the Toledo Fayum Portrait, in: Conservation of paintings and the graphic arts, Preprints of contributions to the Lisbon Congress, October 1972 (London 1972); B. Ramer, Technology, examination and conservation of the Fayum portraits of the Petrie Museum, Studies in Conservation 24, 1 (Febr. 1979)1-13; S.P. Sack-C.Tahk-T.Peters, A technical examination of an ancient Egyptian painting on canvas, Studies in Conservation 26, 1 (1981).

Research aimed at identifying lake on Byzantine icons has been undertaken in a very disjointed fashion but its use has been confirmed in some works. Lake, in which brazil wood red lake predominates, was found in Christ's tunic in the icon of Christ in Majesty from the Church of St Nicholas in Polygyro, see:

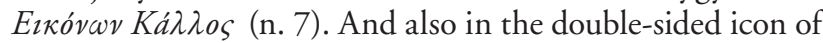
the Crucifixion from the Byzantine and Christian Museum of Athens (inv. no. T 157) (13th-c. phase) where a layer of red lake was found in the hand of the Virgin, see: $\triangle X A E$ (n. 7) 215-45. Lake is also found in a mixture with other pigments or even as an underpaint layer in 13th-c. Western works, mainly on draperies. For example in the works of Duccio di Buoninsegna, the Master of St Francis, and Giotto (see n. 7). In the early Middle Ages kermes and madder were used as dyestuffs in the preparation of red lake, while from 1220 on brazil wood is mentioned in recipes in extremely large quantities and was used from the 12th c. throughout Europe. 
12. A top layer of lake unifies the tones so that volumes are rendered in smooth transitions from light to dark. This technique prevailed later, from the mid-15th c., in the depiction of the Virgin's maphorion, covering the surface of the draperies with a semi-translucent layer of dark red lake. Though the absence of published evidence for this period is a serious drawback, this feature is extremely significant and can be compared as a technical feature with the corresponding evidence from the icons of: the Virgin and Child (inv. no. 32650), the double-sided icon of St Nicholas and the Hodegetria from a private collection in Athens as well as the Christ in Majesty and the Virgin Glykophilousa (see n. 13).

13. We find the same technique on the draperies in another two 13th-c. icons, on which a thin, transparent top layer has been identified. I refer to the Virgin's maphorion on the icon of the Virgin and Child (Benaki Museum, inv. no. 32650) and the Christ Child's blue tunic on the reverse (featuring the Hodegetria) of the double-sided icon from a private collection (see n. 2) and on St Nicholas's phelonion on the main face of that panel: Milanou (n. 2). A thin layer of glaze with a few particles of azurite and a large quantity of binding medium was also applied, above the highlights, on Christ's blue himation in the early 14th-c. icon of Christ in Majesty from the Church of St Nicholas in Po-

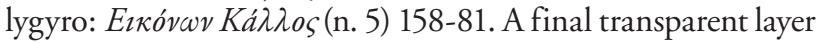
in the form of a green earth glaze is used in similar fashion to cover the paint layers on the Virgin's blue maphorion in the icon of the Virgin Glykophilousa (Benaki Museum, inv. no. 2972):

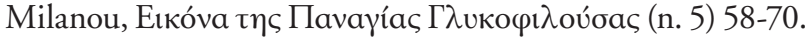

14. Good examples of icons with painted backgrounds can be found in 11th-, 12th- and 13th-c. panels, mainly from Northern Greece but also from Cyprus and Italy. On the late 13th-c. Virgin and Child from Northern Greece (now in a private collection) the figures stand out against a background of warm

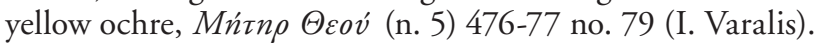
On the late 12th-c. double-sided icon with the Hodegetria and the Man of Sorrows from the Byzantine Collection in Kastoria the figures are painted on a yellow ochre ground which imitates gold, Mńmn $\Theta \varepsilon o v$ (n. 5) 484-85 no. 83 (E. Tsigaridas). The double-sided icon of the Crucifixion (9th, 10th and 13th c.) in the Byzantine and Christian Museum of Athens with 10th-c. yellow-ochre background (see n. 9); and the 12th-c. icon from Mount Athos painted on a red background (BCM, inv. no. T 2739), Acheimastou-Potamianou (n. 5) 18-19 no. 2. Two other icons also have red backgrounds: the Transfiguration and the Raising of Lazarus (H. C. Evans - W. D. Wixom (eds), The Glory of Byzantium (exhibition catalogue, The Metropolitan Museum of Art, New York 1997) 119-20 no. 67A (B. Weyl Carr)

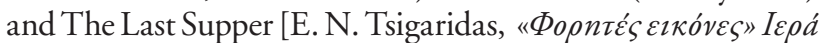

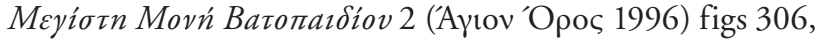
361]. The former is now in the Hermitage Museum, St Petersburg, while the latter is in the Athonite Vatopedi Monastery. The 11th-c. Virgin Enthroned with the Archangels Michael and Gabriel (inv. no. 88) in the Church of St Nicholas in Gournes also has a red background and the double-sided icon from the church of St George Archon in Grammatiko with the early 13th-c. Crucifixion on the obverse has a dark blue background,

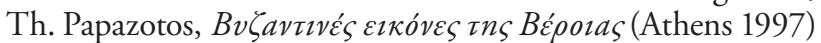
41,45 figs 1, 2. There is also the Benaki Museum 13th-c. icon of the Virgin and Child with Busts of Saints (inv. no. 32650), Milanou, Eıкóva Паvaүía Врєчократоúбa (n. 5) 41-58. From Cyprus there is the 13th-c. Prophet Elijah with red ground from the Katholikon of the Monastery of St John Lampadistis, Mouriki-Papageorgiou (n. 4) 42-3 no. 10 (A. Papageorgiou) and the 14th-c. double-sided icon with the Virgin "of the Tower" on the main face and the Crucifixion on the reverse from the Church of the Taxiarchs, Neo Marmara and the 14th-c. icon of Christ in Majesty which also has a dull green background containing

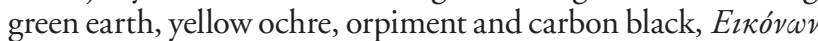
Ká $\lambda \lambda_{0 \varsigma}$ (n. 5) 264-83 and 158-81 respectively. And finally there is the Italian panel of the Virgin Lactans (ca 1260-1280) from Pisa with a dark brownish and blue background, Mńtn $\rho$ Evov (n. 5) 442-43 no. 70 (M. Bacci).

15. Analysis of the pigments was carried out using SEMEDX in the Institute of Geology and Mining Studies (I.G.M.E) by Prof. Vassilis Perdikatsis and George Oikonomou. A JEOL SM-5600 electron microscope was used while qualitative and semi-quantitative results were acquired using the manufacturers' INCA programme.

16. On the 13th-c. double-sided icon of St George and Two Women Saints (BCM, inv. no. T 89) particles of pure quartz were identified in a red layer of cinnabar from St. George's shield. Similarly on the orange-red robe of St Marina on the reverse, pure quartz particles were found in a layer of cinnabar. In the red pigments on this double-sided icon ochre with oxides of trivalent iron and quartz was found, sometimes in pure form and sometimes mixed with lead white. I. Chrysoulakis - T. Chatzedaki

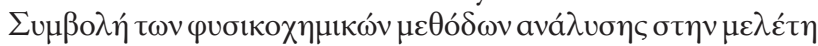

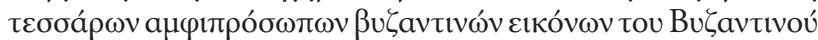

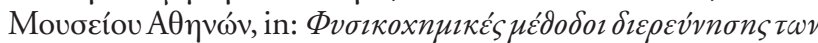

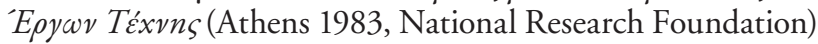
171-93. Quartz particles mixed with lead white were identified on the BCM's two-sided icon of the Crucifixion (9th-, 10thand 13th-c. phases) on the himation of the angel on the left, $\triangle X A E$ (n. 7) 215-45. Pure quartz particles were also found in the Virgin's purple maphorion on the 13th-c. icon of the Virgin and Child with busts of saints, Benaki Museum, inv. no. 32650 (n. 7). The addition of quartz and, after the 14 th c., of glass to the pigment mixtures helps make the paint more transparent and speeds up the drying process in the binding medium. It is worth noting that quartz was also used in Ancient Greek painting for the same reasons. In antiquity (see Theophrastus) and up to the mid-17th c., the clear colourless quartz was called crystal or "ice" (from the Greek words cryos [cold] and stell-o [to array

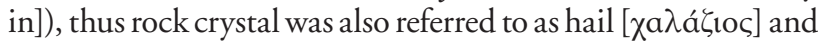
hailstone $[\chi a \lambda a \zeta i ́ n \varsigma \curlywedge \lambda i \theta o c]$. The pigments which have been analysed come from various parts of $\mathrm{Greece}$. In the red and brown colours which contain hydroxides and ferrous oxides or their mixtures combined with pure quartz they produce various hues from yellows and browns to dark reds, V. Perdikatsis, Avá $\lambda u \sigma \eta$

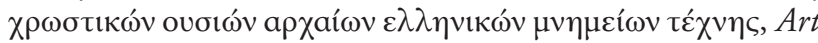
and Technology (Athens 1993) 271-80.

17. From an analysis of 13 th-c. works it has emerged that the ground on another three icons is made up of a mixture of gypsum and chalk (calcium carbonate), that is: on the 13th-c. icon of the Virgin and Child with Busts of Saints, Benaki Museum, 
inv. no. 32650 (see n. 7); on the double-sided icon of the 1st half of the 13th c. from an Athens private collection with St Nicholas and the Virgin and Child ( see n. 2); and on the late 13th-c. double-sided icon from Thessaloniki with Christ on the obverse (BCM, inv. no. T.188), $\triangle X A E$ (n. 7) 215-45.

The type of ground used might well be another indicator of provenance and could perhaps also be used as a criterion for dating the icons. Unfortunately to date far too few studies have been published to give the sort of comprehensive picture from which we can draw any firm general conclusions.

18. Quartz particles were detected in the ground of the icon of the Virgin and Child, Benaki Museum, inv. no. 32650 (see n. 7) and in the double-sided icon of St Nicholas/Virgin and Child (see n. 2), as well as in various icons from the BCM (see n. 17).

19. Pliny mentions this particular technique, explaining that it depends upon the upper layer of paint being thin, as in the various organic lakes or pigments derived from minerals such as azurite, malachite or green earth etc., Pliny the Elder (n. 10) 227-28. Byzantine artists used the same technique, e.g. on the Virgin's maphorion on the icon of the Virgin and Child with Busts of Saints (Benaki Museum, inv. no. 32650; see n. 7).

20. It is worth noting that in the highlights, the lead white is not in its pure form but contains admixtures of chalk and gesso. On the flesh of the right cheek of the funerary portrait of a woman (Benaki Museum, inv. no. 6877) the top layer contains lead white and chalk, Bierbrier (n. 11) 88-95.

21. Discoloration of lake, i.e. fading from long-term exposure to light, has been observed in many Florentine panel paintings of the 14th and 15th c. The phenomenon has been studied on laboratory samples and it was established that the stability of lake under optical and ultraviolet radiation depends on many factors (e.g. type of dyestuff, underpainting, binding agent, type of precipitation, or mixing with inorganic pigments). Lakes which have been artificially aged show a reduction in their red colouring and an increase in brilliance: D. Saunders - S. Kirby, Light-induced colour changes in red and yellow lake pigments, NGTB 15 (1994) 79-97. For example, a damaged surface layer of lake was identified in the Virgin's robe on a panel painting of the
Coronation of the Virgin in the National Gallery in London, A. Burnstock, The fading of the Virgin's robe in Lorenzo Monaco's "Coronation of the Virgin", NGTB 12(1988) 58-65.

22. As early as the Roman period Pliny described a particular technique in which a colour was used as the underpaint to another in order to reinforce or enhance the tone of the surface colour, to lighten or darken it, to give it a warmer or colder hue. $\mathrm{He}$ also referred to an underlayer for azure blue (made up of azurite, ultramarine and indigo) which enhances its violet tint, Pliny the Elder (n. 10) 227-29. In his 14th-c. treatise, Cennino Cennini, following the tradition of earlier artists, mentions that in order to paint the blue mantle of the Virgin you should use two parts sinoper to one part black pigment as underlayer: Cennino d'Andrea Cennini, The Craftsman's Handbook, "Il Libro dell'Arte” (tr. D.V. Thompson, Jr., New York 1960) 54-55.

23. For example 13th- and 14th-c. icons where indigo predominates in the blue draperies. In the double-sided, 13th-c. relief icon of St George with scenes from his life the artist has used indigo mixed with lead white on the saint's blue cloak and on the blue sky on the reverse. On the double-sided icon of the Crucifixion with the Virgin and Child on the reverse (BCM, inv. no. T 169) indigo predominates in the blue draperies of the angel on the left: I. Chrysoulakis - T. Chatzidaki, $\Sigma v \mu \beta o \lambda \eta \dot{\tau} \tau \omega v$

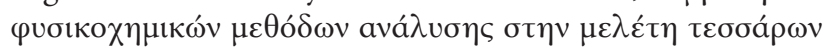

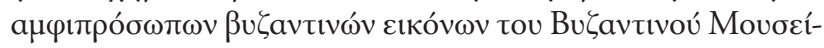

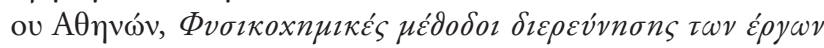

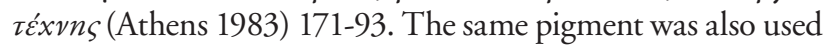
on Christ's blue cloak on the icon of Christ in Majesty from the

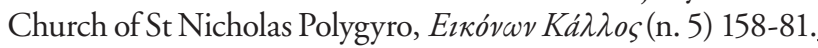

24 A white brushstroke from the Christ Child's tunic (n. 20).

25. Orpiment has also been found in the background of the double-sided icon from Peta in Epirus as well as that of the Crucifixion and the Virgin Pammakaristos in the Byzantine $\mathrm{Mu}-$ seum, in the Crucifixion (10th-c. phase), $\triangle X A E$ (n. 7) and on the Christ in Majesty from the Church of St Nicholas Polygyro,

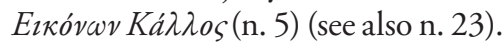




\section{KA $\Lambda Y \Psi \Omega$ MI $\Lambda$ ANOY}

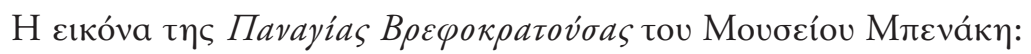

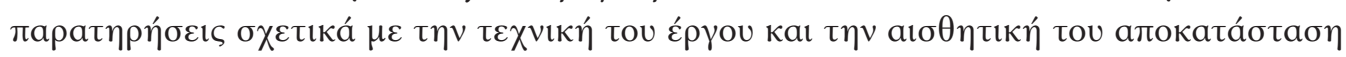

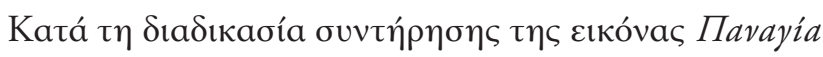

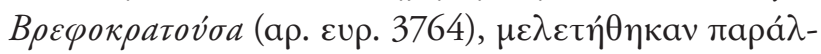

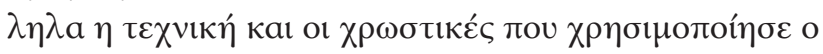

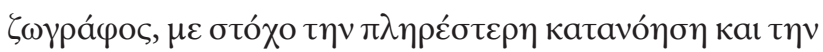

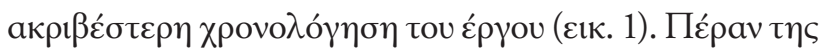

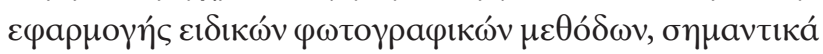

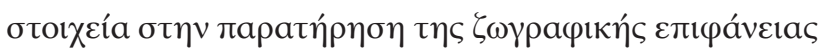

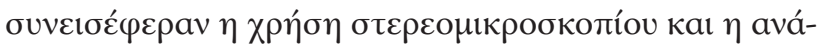

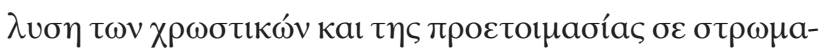

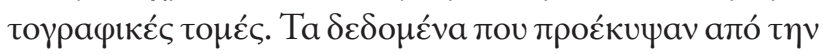

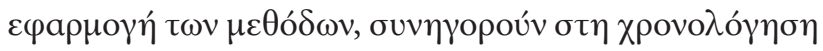

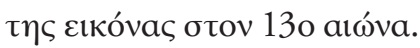

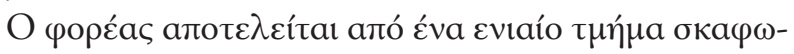

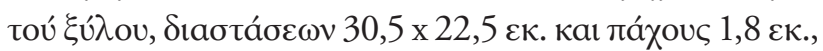

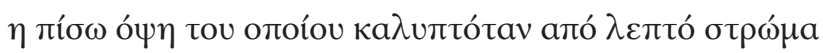

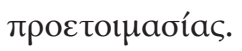

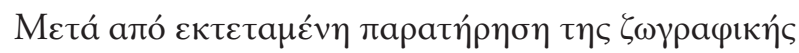

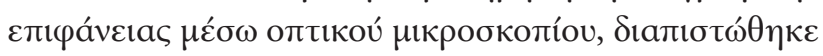

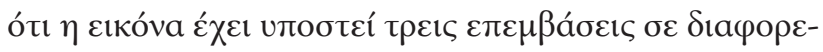

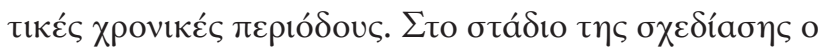

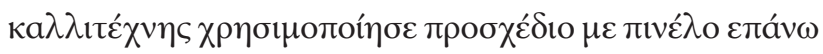

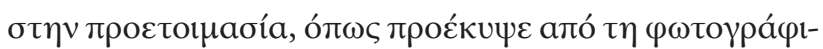

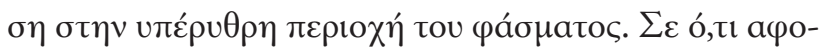

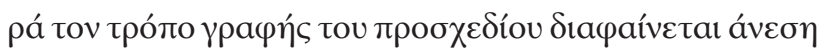

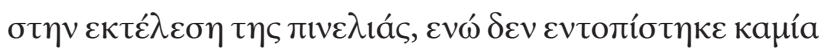

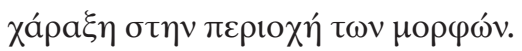

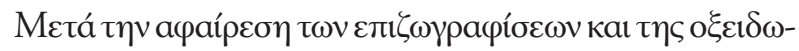

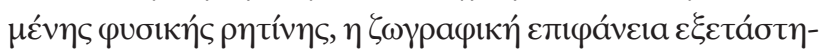

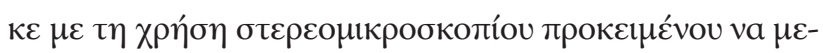

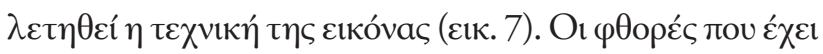

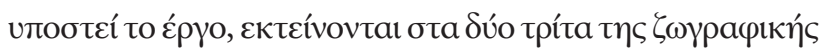

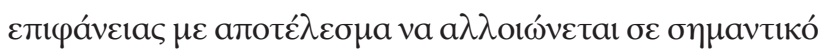

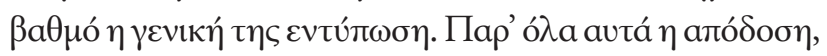

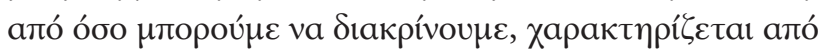

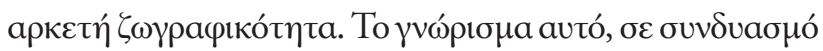

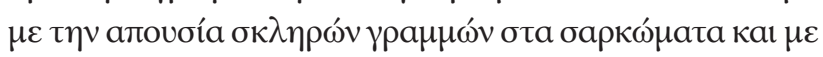

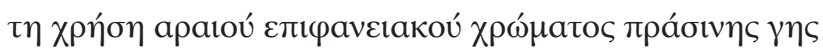

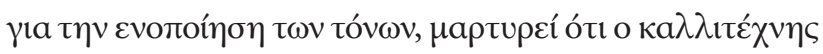

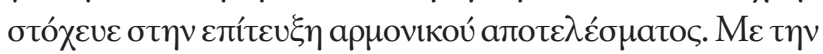

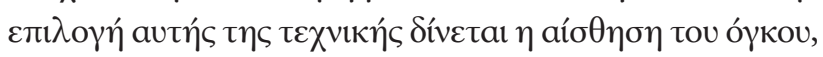

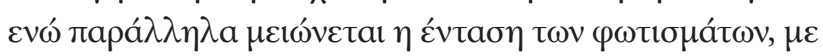

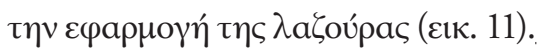

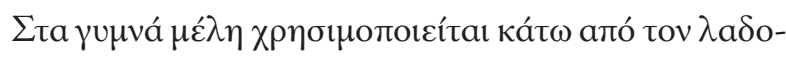

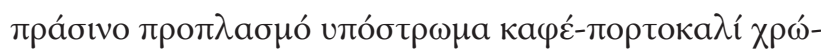

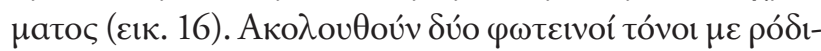

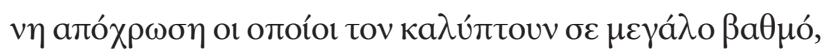

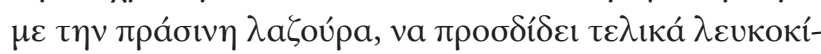

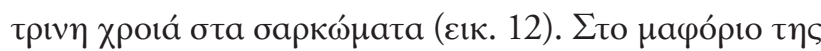

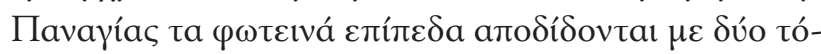

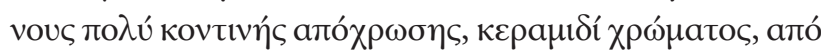

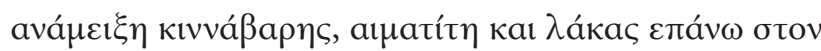

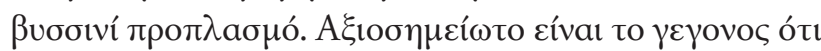

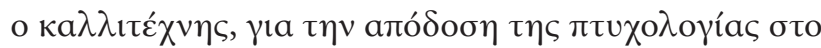

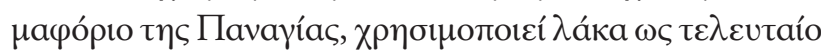

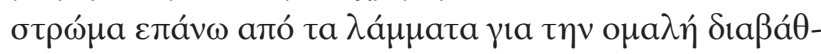

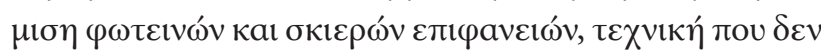

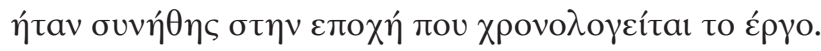

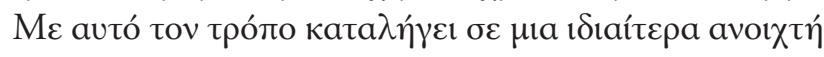

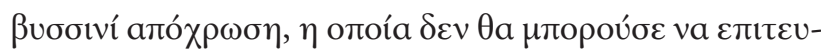

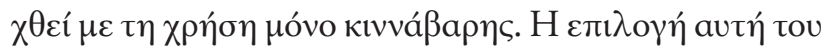

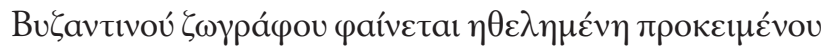

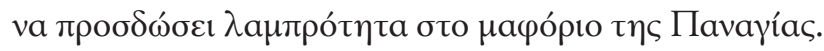

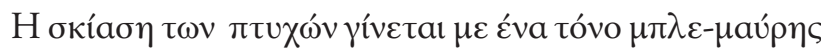

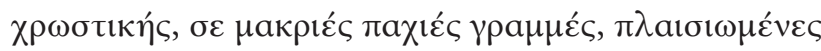

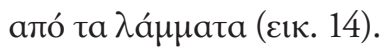

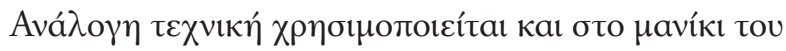

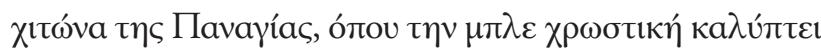

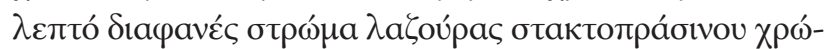

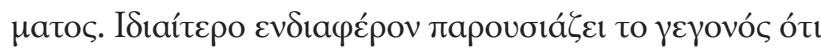

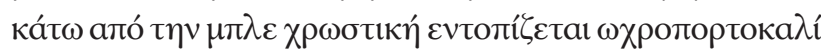

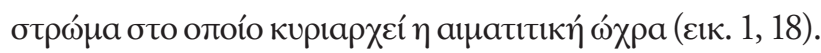

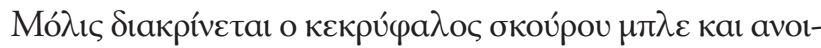

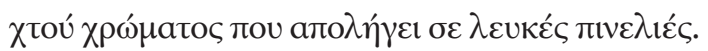

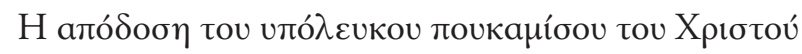

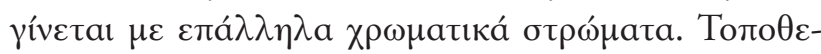

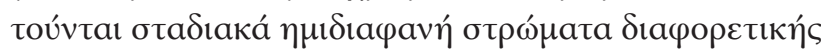

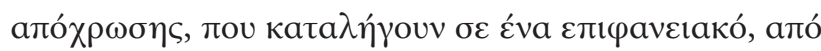

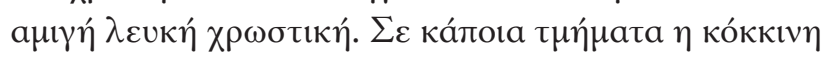

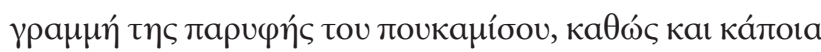

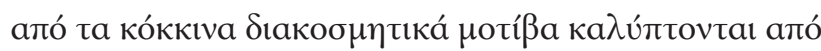

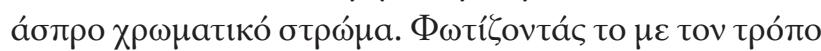

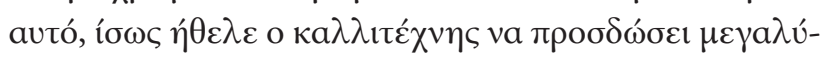

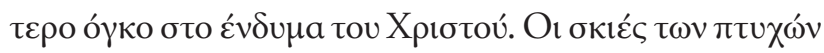

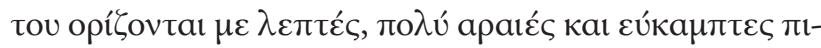




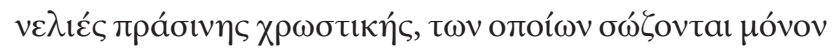
íx $\vee \eta(\varepsilon ı$. 19).

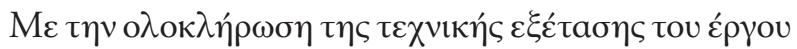

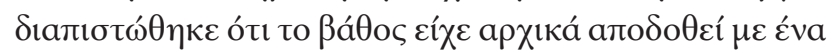

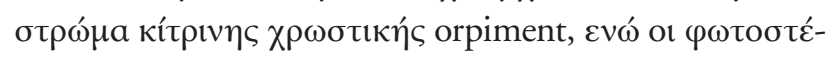

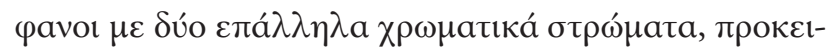

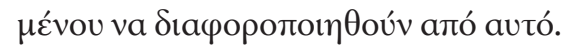

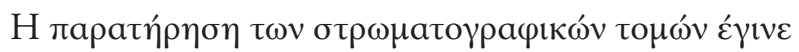

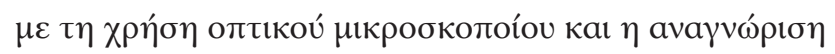

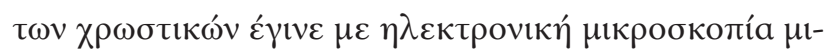

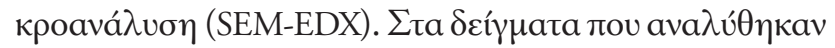

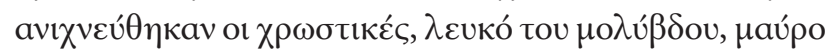

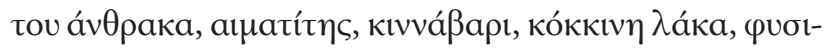

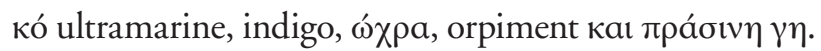

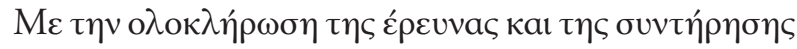

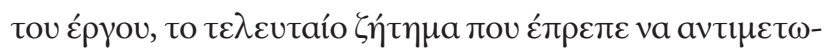

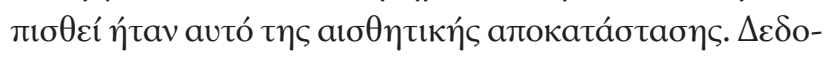

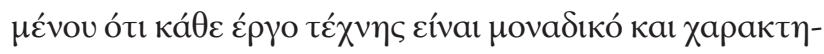

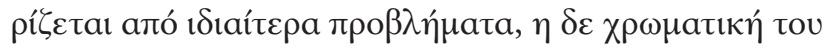

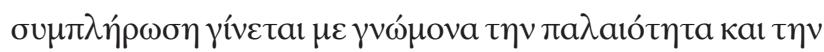

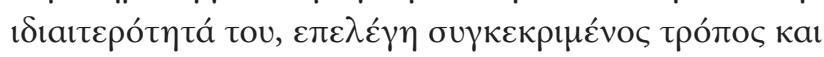

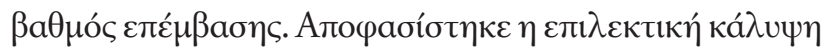

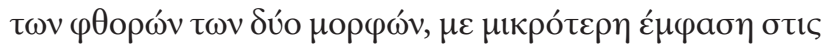

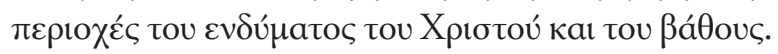

